\title{
Production decision-making system for manufacturing enterprises constrained by carbon reduction policies
}

\author{
Ma Changsong ${ }^{1,2,3} \cdot$ Yuan Tiantong ${ }^{3} \cdot$ Zhong Lei $^{4} \cdot$ Liu Wei $^{4}$
}

Received: 31 December 2020 / Accepted: 9 March 2021

(c) The Author(s) 2021

\begin{abstract}
This paper studies the optimal low carbon production decision system with considered the constraints of carbon emission reduction policy for manufacturing enterprises producing two kinds of products in the free market. Firstly, The research proved the optimal production combination exists and it is unique under the carbon emissions limits, and next, the research analyzed the low-carbon production decision-making system in three situations, which are carbon emission trade decision, green technology input decision, and joint decision. The research results showed that carbon emission permits trade can increase more flexibility to manufacturing enterprises and increase their profits as well. However, the carbon emissions limits set by the government would have an important impact on the production decision system of manufacturing enterprises. Carbon emission permits trade and green technology investment can optimize and improve the production decision system of manufacturing enterprises to a certain extent. Meanwhile, the government's scientific and reasonable formulation of initial carbon quotas would mobilize the enthusiasm and initiative of manufacturing enterprises to participate in carbon emission reduction. The government should also guide and encourage enterprises to invest in and develop low-carbon emission reduction technologies through tax relief, so as to improve carbon emission reduction technologies and its innovations to reduce carbon dioxide emissions.
\end{abstract}

Keywords Carbon emission permits trade $\cdot$ Green technology input $\cdot$ Low carbon $\cdot$ Production decision

\section{Introduction}

In recent years, carbon dioxide $\left(\mathrm{CO}_{2}\right)$ has increased and it had caused many problems that threaten the sustainable development of economy, environment, and many other aspects. For example, the deterioration of climate problems caused by the increase in greenhouse gas emissions has threatened the survival and development of mankind. Many studies showed that at least $90 \%$ of global warming is likely to be caused by human activities [16]. Therefore, to reduce

Yuan Tiantong

9073637@QQ.com

1 Mianyang Teachers' College, Mianyang 621000, China

2 Research Center of Sichuan County Economic Development, Mianyang 621000, China

3 International College, Krirk University, Bangkok 10220, Thailand

4 City College, Southwest University of Science and Technology, Mianyang 621000, China carbon dioxide $\left(\mathrm{CO}_{2}\right)$ emission globally is the consensus of the world to curb the greenhouse effect and implement the carbon emission reduction policy to deal with the deterioration of the human living environment. As an important part of social and economic development, manufacturing enterprises inevitably produce carbon dioxide $\left(\mathrm{CO}_{2}\right)$ in many activities, such as manufacturing, processing, storage, transportation, and so on. In 2011, total carbon emissions from China's industrial sector had exceeded 2.5 billion tons, with manufacturing accounting for nearly $60 \%$ [18]. Since the 1950s, the Scholars have carried out extensive and in-depth researches on manufacturing enterprises' production decisions and obtained rich research results. Regretfully, most of them aim to meet the diversified needs of customers on the premise of minimum total cost or maximum total income, without considered the carbon emissions of enterprises in their production activities. Green low carbon voice is increasing, the government carbon emission reduction policy represented by carbon quota and trading policy has been introduced one after another, reducing carbon dioxide 
$\left(\mathrm{CO}_{2}\right)$ emissions has become a new subject that manufacturing enterprises must face.

\section{Literature review}

More and more production enterprises realize that by relying on green technological innovation and improving energy utilization as much as possible can bring them further profit growth [9, 21]. Braun and Wield [4] introduced the concept of green technology with the background of environmental pollution for the first time, and considered that green technology is a kind of technology to reduce the externality transmitted by the ecological environment in the process of production and consumption. Yu [26] pointed out that the application of green technology can improve industrial productivity greatly, improve the level of green industry, and save social resources significantly [7]. In recent years, with the development of a low-carbon economy, green technology investment has become an indispensable part of enterprise production and operation, and the focus of research has shifted from the original macro level to the micro level enterprise operation gradually [8]. According to previous studies, He and Ma [12] considered that carbon emission resources have become an important enterprise resource gradually. The optimal investment strategy of carbon emission reduction technology is obtained. For example, the green technology cost function should be in line with the reality, which should be accelerated with the increase of emission reduction [12], and the $R \& D$ cost $C R \& D$ function is introduced in the case of carbon emission permits trade [25]. Du et al. [11] considered the production optimization problem of enterprises under the condition of determining market demand. By exploring the existing literatures, producers can obtain emission rights permission through three channels, which are production reduction, purification and purchase, the effectiveness of governance technology investment is proved [6]. Based on the theory of real option,the model of the green technology investment strategy of manufacturers under the condition of technology uncertainty is established [20], and the best time and value function of technology investment is obtained [13]. Zhao and Lv [27] discussed the low-carbonization strategy of enterprises under the carbon quota and trading policy, and analysed the cumulative emission reduction per unit product is affected by the input cost coefficient of low carbon technology and the price of carbon emission right [22]. Since the 1950s, the scholars have carried on the extensive and in-depth research to the enterprise production decision, and has obtained the rich research result, But the goal is to meet the diversified needs of customers under the premise of minimum total cost or maximum total income. Laffont and Tirole [19] started to study production decision-making under carbon cap and trade policy, as well as the production decision in the case of tradable carbon emission rights. By establishing a twostage production model, the conclusion of carbon quota and trading mechanism can effectively reduce pollution is obtained. Dobos [10] compared the changes of enterprise cost before and after the implementation of carbon emission and quota policy with the dynamic Arrow-Karlin model, discussed the influence of emission trading on enterprise production decision, and obtained the optimal output of enterprise eventually. Based on the optimal order quantity and retail price of the retailer, the influence of carbon emission permits trade on the retailer's optimal order quantity, optimal pricing and maximum expected profit was analyzed [14]. Chaabane et al. [5] considered a sustainable supply chain model in the case of emission trading, which indicated the carbon quota and trading strategy can reduce pollution emissions effectively, and its cost-effective can be achieved through effective carbon management strategy. Benjaafar and Elhafsi [2] as the world's leading scholars in this field. Benjaafar and Elhafsi [2] has incorporated carbon emission factors into business operations, which was the first study to incorporate carbon emission constraints into the supply chain system. They studied the impact of carbon quota and trading policies on enterprise investment, production, inventory, and ordering decision-making behavior, and concluded that enterprises can maximize their profits by modifying the number of orders by considering carbon quota policy [15, 23]. Based on the study conducted by Benjaafar and Elhafsi [2], Benjaafar et al. [3] proposed an effective production process, production plan and inventory management strategy are/were designed, and the conclusion/concluded that appropriate green technology input can increase the profit of the enterprise is obtained [17]. To sum up, few studies focus on the production decision system considering carbon emission permits trade and green technology input under carbon emission reduction policy. Thereby, this paper takes the production decision system of manufacturing enterprises as the research content from the micro perspective, and studied the specific problem of optimizing the production decision system of manufacturing enterprises through carbon emission permits trade and green technology input under the constraints of carbon emission reduction policy.

\section{Problem description and hypothesis}

This paper assumes that there is one manufacturing enterprise and two consumer groups in the market, who are all facing random demand. At the end of the sales period, the study will take a residual value of the remaining inventory into the calculation. Meanwhile, manufacturing enterprises will also face shortage losses. Under the carbon emissions limits policy, the government has set a maximum carbon 
emission, that is, carbon emissions limits $K(>0)$. For ease of expression, the symbols in the model mean the following (Table 1).

On the other hand, in the context of a low-carbon economy, by considering government quotas, carbon emission permits trade and the implementation of green technology inputs for carbon emission purification treatment, as well as single-cycle production and single-emission scenario, manufacturing enterprises will consider the low-carbon production decision-making systems in a different scenario, such as carbon emission permits trade and green technology inputs, and make the following assumptions:

1. Both products are sold in a short period of time. The market is stable and the prices of the products remain unchanged during the period of sale.

2. $p_{i} \geq c_{i}>v_{i}>0$, in which $i=1,2$. This condition shows that every product sold in the consumer market will bring profit growth to manufacturing enterprises. On the other hand, if a product is not sold, the enterprise will suffer a loss of profit.

3. Assuming that the manufacturing enterprise must maintain normal production and be rational, it will weigh the benefits and costs of carbon emission permits trade and green technology input.

4. Considering that manufacturing enterprises can reduce carbon emissions through their green technology inputs, the input cost of green technology $c_{i}(T)$ is continuously differentiable, which accelerates with the increase of green technology input level $T$, and the value range of which is from 0 to $1, c^{\prime}(T)>0, c^{\prime \prime}(T)>0, c(0)=c_{. k}(T)$ is carbon emissions per unit product for green technology investment, $k^{\prime}(T)<0, k^{\prime \prime}(T) \geq 0$, and $k(0)=k$.
5. Defining $\theta_{i}\left(Q_{i}\right)=\frac{1}{k_{i}\left(T_{i}\right)} \frac{\mathrm{d} \pi\left(Q_{1}, Q_{2}\right)_{Q_{i}}}{\mathrm{~d} Q_{i}} ; i=1,2$ as profits arising from the unit carbon emission rights of the products $i$ of the manufacturing enterprise, i.e. $\theta_{i}\left(Q_{i}\right)=\frac{1}{k_{i}\left(T_{i}\right)}\left(\left(p_{i}+r_{i}-c_{i}\left(T_{i}\right)\right)-\left(p_{i}+r_{i}-v_{i}\right) F\left(Q_{i}\right)\right)$. When $T_{i}=0, \quad \theta_{i}\left(Q_{i}\right) \quad$ degenerates into $\theta_{i}\left(Q_{i}\right)=\frac{1}{k_{i}}$ $\left(\left(p_{i}+r_{i}-c_{i}\right)-\left(p_{i}+r_{i}-v_{i}\right) F\left(Q_{i}\right)\right) ; i=1,2$.

\section{Basic model}

In this paper, the random demand of the two products are presented by $\mathrm{x}$ and $\mathrm{y}$ respectively, each obeys the distribution of probability density functions of $\mathrm{f}_{1}(\bullet)$ and $\mathrm{f}_{2}(\bullet)$ for the two product demands respectively. $p_{i}, c_{i}, r_{i}, v_{i}$ are the retail price per unit product, production cost, residual value at the end of sales and opportunity cost of shortage. If the production of the manufacturing enterprise is $Q_{1}$ and $Q_{2}$, the expected profit function of the manufacturing enterprise to produce the product $i$ is as follows:

$\pi^{n}\left(Q_{i}\right)=\left(p_{i}+r_{i}-c_{i}\right) Q_{i}-\left(p_{i}+r_{i}-v_{i}\right) \int_{0}^{Q_{i}} F_{i}(x) \mathrm{d} x-r_{i} \mu_{i}$.

The total expected profit function of the manufacturing enterprise is:

$$
\begin{aligned}
\pi^{n}(\mathbf{Q}) & =\sum_{i=1}^{2} \pi^{n}\left(Q_{i}\right) \\
& =\sum_{i=1}^{2}\left(\left(p_{i}+r_{i}-c_{i}\right) Q_{i}-\left(p_{i}+r_{i}-v_{i}\right) \int_{0}^{Q_{i}} F_{i}(x) \mathrm{d} x-r_{i} \mu_{i}\right) .
\end{aligned}
$$

Table 1 Meaning of symbols in the model

\begin{tabular}{ll}
\hline Parameter & Parametric meaning \\
\hline$f_{1}(\bullet)$ and $f_{2}(\bullet)$ & Random demand probability density function for product 1 and product 2 \\
$F_{1}(\bullet)$ and $F_{2}(\bullet)$ & Random demand distribution function for products 1 and 2 \\
$f(\bullet, \bullet)$ & Joint stochastic demand probability density function for product 1 and product 2 \\
$F(\bullet, \bullet)$ & Joint stochastic demand distribution function for product 1 and product 2 \\
$p_{1}$ and $p_{2}$ & Retail prices per unit of product 1 and product 2 \\
$r_{1}$ and $r_{2}$ & Shortage opportunity cost per unit of product 1 and product 2 \\
$v_{1}$ and $v_{2}$ & Residual value of product 1 and product 2 per unit at the end of sale \\
$K$ & Government-mandated maximum carbon emissions \\
$W$ & Trading volume in external carbon emission permits trade markets \\
$w$ & Carbon emission price per unit \\
$Q_{1}$ and $Q_{2}$ & Production of products 1 and 2 \\
$T$ & Green technology input level for manufacturing enterprises \\
$c_{1}$ and $c_{2}$ & Production cost per unit of product 1 and product 2 without green technology input \\
$c_{1}(T)$ and $c_{2}(T)$ & Production cost per unit of product 1 and product 2 after green technology input \\
$k_{1}$ and $k_{2}$ & Carbon emissions per unit of product 1 and product 2 without green technology input \\
$k_{1}(T)$ and $k_{2}(T)$ & Carbon emissions per unit of product 1 and product 2 after green technology input \\
\hline &
\end{tabular}


Among them, $\mathbf{Q}=\left(Q_{1}, Q_{2}\right)$. The decision goal of manufacturing enterprises in this case is to maximize the expected profit.

In the absence of carbon emissions limits constraint, the classical Newsboy Model shows that the optimal production capacity $Q_{i}^{*}$ of manufacturing enterprises production $i$ is:

$Q_{i}^{*}=F^{-1}\left(\frac{p_{i}+r_{i}-c_{i}}{p_{i}+r_{i}-v_{i}}\right) ; i=1,2$.

In the absence of carbon emissions limits constraint, the expected profit of the manufacturing enterprise is:

$$
\begin{aligned}
\pi^{n}(\mathbf{Q})= & \sum_{i=1}^{2} \pi^{n}\left(Q_{i}^{*}\right) \\
= & \sum_{i=1}^{2}\left(\left(p_{i}+r_{i}-c_{i}\right) F^{-1}\left(\frac{p_{i}+r_{i}-c_{i}}{p_{i}+r_{i}-v_{i}}\right)\right. \\
& \left.\quad-\left(p_{i}+r_{i}-v_{i}\right) \int_{0}^{F^{-1}\left(\frac{p_{i}+r_{i}-c_{i}}{p_{i}+r_{i}-v_{i}}\right)} F_{i}(x) \mathrm{d} x-r_{i} \mu_{i}\right) .
\end{aligned}
$$

W hen the government sets a maximum carbon emission limits, i.e. $K(>0)$, the carbon emissions generated by manufacturing enterprises in carrying out production activities can not exceed this mandatory limit. The expected profit function of the manufacturing enterprise in this case is:

$\left\{\begin{array}{l}\pi^{K}\left(\mathbf{Q}_{\mathbf{K}}\right)=\sum_{i=1}^{2}\left(\left(p_{i}+r_{i}-c_{i}\right) Q_{i K}-\left(p_{i}+r_{i}-v_{i}\right) \int_{0}^{Q_{i K}} F_{i}(x) \mathrm{d} x-r_{i} \mu_{i}\right) . \\ \text { s.t. } \sum_{i=1}^{2} k_{i} Q_{i} \leq K\end{array}\right.$

Among them, $\mathbf{Q}_{\mathbf{K}}=\left(Q_{1 K}, Q_{2 K}\right)$. The decision goal of manufacturing enterprises in this case is to maximize the expected profit.

Proposition 1 When the government sets the carbon emissions limits $K(>0)$, the optimal production mix that maximizes the expected profit of the manufacturing enterprise exists and is unique, and: (1) when $K \geq \sum_{i=1}^{2} k_{i} Q_{i}^{*}$, then, $Q_{1 K}^{*}=Q_{1}^{*}, Q_{2 K}^{*}=Q_{2}^{*}$. (2) If $K<\sum_{i=1}^{2} k_{i} Q_{i}^{*}$, then $Q_{1 K}^{*}$ and $Q_{2 K}^{*}$ meet $K=\sum_{i=1}^{2} k_{i} Q_{i}^{*}$ and $\theta_{1}\left(Q_{1 K}^{*}\right)=\theta_{2}\left(Q_{2 K}^{*}\right)$.

Thereby, Proposition 1 shows that due to the existence of carbon emissions limits set by the government, the production decisions of manufacturing enterprises will be affected by carbon emissions limits. When $K<\sum_{i=1}^{2} k_{i} Q_{i}^{*}$, that is, the initial carbon quota set by the government was too high, which is higher than the carbon dioxide $\left(\mathrm{CO}_{2}\right)$ produced by the manufacturing enterprise in the optimal production decision under the condition of no carbon quota, so the optimal decision of the enterprise degenerates into the optimal decision without carbon emissions limits constraint. At this time, there was a carbon emission right surplus. When $K<\sum_{i=1}^{2} k_{i} Q_{i}^{*}$, the decision of manufacturing enterprises was restricted by the government's carbon emissions limits. At this time, there was no carbon emission right surplus.

In order to discuss the impact of carbon emissions limits on the decision-making of manufacturing enterprises, there are the following inferences:

Corollary 1 The optimal production of manufacturing enterprises under the constraints of carbon emissions limits is $Q_{1 K}^{*} \leq Q_{1}^{*}, Q_{2 K}^{*} \leq Q_{2}^{*}$.

Corollary 1 shows that the optimal production of manufacturing enterprises under the constraint of carbon emissions limits is less than that under the constraint of no carbon emissions limits.

Corollary 2 The expected profit of the manufacturing enterprise under the carbon emissions limits is:

$$
\begin{aligned}
& \pi^{K}\left(Q_{1 K}^{*}, Q_{2 K}^{*}\right)=\left\{\begin{array}{cc}
\pi^{n}\left(Q_{1}^{*}, Q_{2}^{*}\right) & K \geq k_{1} Q_{1}^{*}+k_{2} Q_{2}^{*} \\
\pi^{n}\left(Q_{1 K}^{*}, Q_{2 K}^{*}\right) & K<k_{1} Q_{1}^{*}+k_{2} Q_{2}^{*}
\end{array}\right. \text { and } \\
& \pi^{K}\left(Q_{1 K}^{*}, Q_{2 K}^{*}\right) \leq \pi^{n}\left(Q_{1}^{*}, Q_{2}^{*}\right) .
\end{aligned}
$$

Corollary 2 shows that the expected profit of the manufacturing enterprise under the carbon emissions limits constraint is less than the expected profit under the carbon-free limit constraint.

\section{Extended model}

Carbon cap and trade policy is a policy means to regulate carbon emissions through the market. Under the constraints of carbon cap and trading policy, the government sets maximum carbon emission limits, that is, carbon emissions limits $K(>0)$. Manufacturing enterprises cannot produce carbon dioxide emissions in manufacturing activities beyond the mandatory limits set by the government, but manufacturers with insufficient carbon emission quotas can purchase carbon emission rights from manufacturing enterprises with excess carbon emission quotas in the external carbon emission permits trade market. Manufacturers with sufficient carbon quotas can profit by selling excess carbon quotas in the external carbon emission permits trade market. Simultaneously, more and more manufacturing enterprises realize that the implementation of green technology such as investment in carbon emission purification during the manufacturing process, which can reduce the $\mathrm{CO} 2$ emissions per unit product and save carbon emission rights.

Carbon emission purification in the manufacturing process of products can reduce the $\mathrm{CO}_{2}$ emissions per unit product and obtain the saving of carbon emission rights. Therefore, this paper will be discussed in three situations: 
1. Under the carbon emissions limits, the manufacturing enterprise will consider making a decision on trading carbon emission rights;

2. Under the carbon emissions limits, manufacturing enterprises will consider making decisions on green technology inputs;

3. Under the carbon emissions limits, manufacturing enterprises will consider a combination of carbon emissions trading and green technology inputs.

\subsection{Case I: decision-making on carbon emissions trading}

First, under the constraints of carbon emissions limits, manufacturing enterprises can not optimize the production of all categories of products at the same time, and will only make decisions on carbon emissions trading. Among them, $W$ is the trading volume of carbon emission rights in the external carbon emission permits trade market. $w$ is the price of unit carbon emission rights. The expected profit function of the manufacturing enterprise in this case is:

$$
\left\{\begin{array}{l}
\pi^{e}\left(\mathbf{Q}_{\mathbf{e}}\right)= \\
\sum_{i=1}^{2}\left(\left(p_{i}+r_{i}-c_{i}\right) Q_{i e}-\left(p_{i}+r_{i}-v_{i}\right) \int_{0}^{Q_{i e}} F_{i}(x) d x-r_{i} \mu_{i}\right)-w W \\
\text { s.t. } \sum_{i=1}^{2} k_{i} Q_{i}=K+W
\end{array}\right.
$$

Among them, $\mathbf{Q}_{\mathbf{e}}=\left(Q_{1 e}, Q_{2 e}\right)$. The decision goal of manufacturing enterprises in this case is to maximize the expected profit.

$\sum_{i=1}^{2} k_{i} Q_{i}=K+W$ means that the total carbon emissions of the manufacturing enterprise must be equal to the sum of the initial carbon emission quota of the government and the amount of carbon emissions trading in the external carbon emission permits trade market. Among them:

- When $W>0$, it meant that manufacturers would buy carbon quotas from the external carbon emission permits trade market;

- When $W=0$, it meant that manufacturers would not trade carbon emission rights in the external carbon emission permits trade market;

- When $W<0$, it meant that manufacturers would sell inexhaustible quotas in the external carbon emission permits trade market.

Proposition 2 The manufacturing enterprise carries on the carbon emission transaction decision, causes the manufacturing enterprise to expect the profit maximization the optimal production combination to exist and unique, the optimal production quantity combination is $Q_{e}^{*}=F^{-1}\left(\frac{p_{i}+r_{i}-c_{i}-w k_{i}}{p_{i}+r_{i}-v_{i}}\right) ; i=1,2, \quad$ and satisfies $\theta_{1}\left(Q_{1 e}^{*}\right)=\theta_{2}\left(Q_{2 e}^{*}\right)=w$, the carbon emission right trading volume is $W_{e}^{*}=\sum_{i=1}^{2} k_{i} Q_{i e}^{*}-K$.

Proposition 2 shows that under the constraint of carbon emissions limits, the manufacturing enterprise must satisfy the condition of $\theta_{1}\left(Q_{1 e}^{*}\right)=\theta_{2}\left(Q_{2 e}^{*}\right)$ under the optimal production decision, otherwise the manufacturing enterprise can obtain higher expected profit by producing more products 1 or 2 . At the same time:

When $\theta_{1}\left(Q_{1 e}^{*}\right)=\theta_{2}\left(Q_{2 e}^{*}\right)>w$, the manufacturer of the unit carbon emission right expected the profit to increase higher than the price of the unit carbon emission right, and the manufacturer would buy the carbon emission right to produce more products to obtain more profits.

When $\theta_{1}\left(Q_{1 e}^{*}\right)=\theta_{2}\left(Q_{2 e}^{*}\right)<w$, the manufacturer of the unit's carbon emission right expected the profit to increase less than one unit's carbon emission right price, and the manufacturer would sell the carbon emission right.

When $\theta_{1}\left(Q_{1 e}^{*}\right)=\theta_{2}\left(Q_{2 e}^{*}\right)=w$, the manufacturer expected the profit increase to be equal to the price of one unit of carbon emission right, and the manufacturer would not trade the carbon emission right. In this case, the manufacturing enterprise has an optimal decision, which makes the enterprise expect the maximum profit.

The following propositions can be further obtained:

\section{Corollary 3}

1. if $\theta_{1}\left(Q_{1 K}^{*}\right)=\theta_{2}\left(Q_{2 K}^{*}\right)=w$, then, $Q_{1 K}^{*}=Q_{1 e}^{*}<Q_{1}^{*}$ $Q_{2 K}^{*}=Q_{2 e}^{*}<Q_{2}^{*}$.

2. if, $\theta_{1}\left(Q_{1 K}^{*}\right)=\theta_{2}\left(Q_{2 K}^{*}\right)<w$, then, $Q_{1 e}^{*}<Q_{1 K}^{*}<Q_{1}^{*}$ $Q_{2 e}^{*}<Q_{2 K}^{*}<Q_{2}^{*}$.

3. if, $\theta_{1}\left(Q_{1 K}^{*}\right)=\theta_{2}\left(Q_{2 K}^{*}\right)>w$, then, $Q_{1 K}^{*}<Q_{1 e}^{*}<Q_{1}^{*}$ $Q_{2 K}^{*}<Q_{2 e}^{*}<Q_{2}^{*}$.

Corollary 3 shows when $\theta_{1}\left(Q_{1 K}^{*}\right)=\theta_{2}\left(Q_{2 K}^{*}\right)<w$, it means that the increase in profits from obtaining an additional unit of carbon emission rights under the carbon emissions limits is less than the cost of buying carbon emission rights, and manufacturers will consider selling carbon emission rights. Production of products 1 and 2 is reduced at the same time.

When $\theta_{1}\left(Q_{1 K}^{*}\right)=\theta_{2}\left(Q_{2 K}^{*}\right)>w$, it meant that the increase in profits from acquiring an additional unit of carbon emission rights under the carbon emission limits was greater than the cost of buying carbon emission rights, and manufacturers would buy carbon emission rights to produce more products. 
Production of product 1 and product 2 increased at the same time.

When $\theta_{1}\left(Q_{1 K}^{*}\right)=\theta_{2}\left(Q_{2 K}^{*}\right)=w$, it means that the increase in profits from the acquisition of an additional unit of carbon emission rights under the carbon emissions limits was equal to the cost of buying carbon emission rights, and manufacturers would not trade carbon emission rights.

Corollary 3 shows that under the carbon emissions limits constraint, the optimal production of the product after the manufacturing enterprise makes the decision of carbon emission right trading $i ;(i=1,2)$ is lower than that of the product without carbon emissions limits $i ;(i=1,2)$. The relationship with the optimal production of the product $i ;(i=1,2)$ under the carbon emissions limits mainly depends on the expected profit increase per unit carbon emission right.

$$
\begin{aligned}
& \text { Corollary } 4 \text { When } \\
& \left(\pi^{n}\left(Q_{1}^{*}, Q_{2}^{*}\right)-\pi^{e}\left(Q_{1 e}^{*}, Q_{2 e}^{*}\right)\right) .
\end{aligned}
$$

1. If $K>K^{*}$, then, $\pi^{e}\left(Q_{1 e}^{*}, Q_{2 e}^{*}\right)>\pi^{n}\left(Q_{1}^{*}, Q_{2}^{*}\right) \geq \pi^{K}$ $\left(Q_{1 K}^{*}, Q_{2 K}^{*}\right)$.

2. If $K=K^{*}$, then, $\pi^{e}\left(Q_{1 e}^{*}, Q_{2 e}^{*}\right)=\pi^{n}\left(Q_{1}^{*}, Q_{2}^{*}\right)>\pi^{K}$ $\left(Q_{1 K}^{*}, Q_{2 K}^{*}\right)$.

3. If $K<K^{*}$, then, $\pi^{n}\left(Q_{1}^{*}, Q_{2}^{*}\right)>\pi^{e}\left(Q_{1 e}^{*}, Q_{2 e}^{*}\right) \geq \pi^{K}$ $\left(Q_{1 K}^{*}, Q_{2 K}^{*}\right)$.

Corollary 4 shows that under the constraints of carbon emissions limits, manufacturing enterprises can increase the expected profits of manufacturing enterprises by buying or selling carbon emission rights, so the expected profits of manufacturing enterprises are always higher than those under carbon emissions limits, and whether the expected profits are higher than those under carbon emissions limits mainly depends on the initial carbon quota of government. Only when the government gives a looser initial carbon quota, the expected profit of the manufacturing enterprise will be higher than the expected profit under the quota.

Analysis of the above propositions and inferences shows that when manufacturing enterprises produce carbon dioxide $\left(\mathrm{CO}_{2}\right)$ in optimal production ${ }_{2}$ If the emissions are below the government's carbon emissions limits, the company has the possibility of remaining carbon emission rights, and the company can sell the remaining carbon emission rights on the external carbon emission permits trade market for profit. Conversely, when the manufacturer optimally produces the carbon dioxide $\left(\mathrm{CO}_{2}\right)$ produced ${ }_{2}$ When the emissions are higher than the carbon emissions limits set by the government, the production decisions of enterprises are affected by the carbon emissions limits set by the government, and enterprises will purchase carbon emission rights in the external carbon emission permits trade market to maintain production.

\subsection{Case II: green technology input decision-making}

Second, under the carbon emissions limits, the manufacturing enterprise can not optimize the production of all kinds of products at the same time, will only carry on the green technology investment to obtain the carbon emission right saving, obtains the additional carbon emission right in disguise. Manufacturing enterprises to product 1 and product 2 green technology investment. The expected profit function of the manufacturing enterprise in this case is:

$$
\left\{\begin{array}{l}
\pi^{t}\left(\mathbf{Q}_{\mathbf{t}}, \mathbf{T}\right)= \\
\sum_{i=1}^{2}\left(\left(p_{i}+r_{i}-c_{i}\left(T_{i}\right)\right) Q_{i t}-\left(p_{i}+r_{i}-v_{i}\right) \int_{0}^{Q_{i t}} F_{i}(x) d x-r_{i} \mu_{i}\right) \\
\text { s.t. } \sum_{i=1}^{2} k_{i}\left(T_{i}\right) Q_{i t} \leq K
\end{array}\right.
$$

Among them, $\mathbf{Q}_{\mathbf{t}}=\left(Q_{1 t}, Q_{2 t}\right) \mathbf{T}=\left(T_{1}, T_{2}\right)$. The decision goal of manufacturing enterprises in this case is to maximize the expected profit.

Proposition 3 When manufacturing enterprises invest in both product 1 and product 2 in green technology, the optimal green input level and optimal production combination that make manufacturing enterprises expect to maximize profits exist and are unique, and the optimal production combination is $Q_{i t}^{*} ;(i=1,2)$. And satisfied type 8 , the optimal green technology input level is. $T_{1 t}^{*} \in(0,1) ; T_{2 t}^{*} \in(0,1)$.

Proposition 3 shows that under the constraint of carbon emissions limits, manufacturing enterprises reduce the carbon emission level per unit product through green technology input when the carbon dioxide $\left(\mathrm{CO}_{2}\right.$ produced by their optimal production is produced ${ }_{2}$ If the emissions are lower than the carbon emissions limits set by the government, the production decision of the enterprise will not be affected by the carbon emissions limits set by the government, and the manufacturing enterprise will not invest in green technology. The optimal production decision of the enterprise is the optimal production decision when the carbon dioxide $\left(\mathrm{CO}_{2}\right)$ is produced by the optimal production of the enterprise ${ }_{2}$ When the emissions are higher than the carbon emissions limits set by the government, the production decision of the enterprise is affected by the carbon emissions limits set by the government, and the manufacturing enterprise will invest in green technology.

The following propositions can be further obtained:

Corollary $5 Q_{1 K}^{*} \leq Q_{1 t}^{*} \leq Q_{1}^{*} Q_{2 K}^{*} \leq Q_{2 t}^{*} \leq Q_{2}^{*}$.

Corollary 5 shows that under the carbon emissions limits constraint, the optimal production of the products $i ;(i=1,2)$ after the green technology input decision is not lower than the optimal production of the carbon emissions limits. 
Corollary $6 \pi^{K}\left(\mathbf{Q}_{\mathbf{K}}^{*}\right) \leq \pi^{t}\left(\mathbf{Q}_{\mathbf{t}}^{*}, \mathbf{T}^{*}\right) \leq \pi^{*}\left(\mathbf{Q}^{*}\right)$.

Corollary 6 shows that under the constraint of carbon emissions limits, appropriate green technology input can increase the expected profit of production enterprises.

\subsection{Case III: decision-making on carbon emission permits trade and green technology portfolio.}

Third, under the constraints of carbon emissions limits, manufacturing enterprises can not optimize the production of all kinds of products at the same time, and will implement the combination decision of carbon emission permits trade and green technology input.Manufacturing enterprises to product 1 and product 2 green technology investment. The expected profit function of the manufacturing enterprise in this case is:

$$
\left\{\begin{array}{l}
\pi^{c}\left(\mathbf{Q}_{\mathbf{c}}, \mathbf{T}_{\mathbf{c}}\right)= \\
\sum_{i=1}^{2}\left(\left(p_{i}+r_{i}-c_{i}\left(T_{i c}\right)\right) Q_{i c}-\left(p_{i}+r_{i}-v_{i}\right) \int_{0}^{Q_{i c}} F_{i}(x) d x-r_{i} \mu_{i}\right)-w W \\
\text { s.t. } \sum_{i=1}^{2} k_{i}\left(T_{i c}\right) Q_{i c}=K+W
\end{array}\right.
$$

Among them, $\mathbf{Q}_{\mathbf{c}}=\left(Q_{1 c}, Q_{2 c}\right) \mathbf{T}_{\mathbf{c}}=\left(T_{1 c}, T_{2 c}\right)$. The decision goal of manufacturing enterprises in this case is to maximize the expected profit.

$\sum_{i=1}^{2} k_{i}\left(T_{i c}\right) Q_{i c}=K+W$ means that the total carbon emissions of the manufacturing enterprise must be equal to the sum of the initial carbon emission quota of the government and the amount of carbon emissions trading in the external carbon emission permits trade market. Among them:

When $W>0$, it meant that manufacturers would buy carbon quotas from the external carbon emission permits trade market;

When $W=0$ it meant that manufacturers would not trade carbon emission rights in the external carbon emission permits trade market;

When $W<0$, it meant that manufacturers would sell inexhaustible quotas in the external carbon emission permits trade market.

$$
\text { Define } \theta_{1}(T)=\frac{\left(\left(c_{1}\left(T_{1}\right)-c_{1}\right) Q_{1}+\left(c_{2}\left(T_{2}\right)-c_{2}\right) Q_{2}\right)_{T_{1}}^{\prime}}{\left(\left(k_{1}-k_{1}\left(T_{1}\right)\right) Q_{1}+\left(k_{2}-k_{2}\left(T_{2}\right)\right) Q_{2}\right)_{T_{1}}^{\prime}} \text { as the mar- }
$$
ginal cost of the unit carbon emission right generated by the green technology input of the manufacturing enterprise to product 1 , that is $; \theta_{1}(T)=-\frac{c_{1}^{\prime}\left(T_{1}\right)}{k_{1}^{\prime}\left(T_{1}\right)}$.

Define $\theta_{2}(T)=\frac{\left(\left(c_{1}\left(T_{1}\right)-c_{1}\right) Q_{1}+\left(c_{2}\left(T_{2}\right)-c_{2}\right) Q_{2}\right)_{T_{2}}^{\prime}}{\left(\left(k_{1}-k_{1}\left(T_{1}\right)\right) Q_{1}+\left(k_{2}-k_{2}\left(T_{2}\right)\right) Q_{2}\right)_{T_{2}}^{\prime}}$ as the marginal cost of the unit carbon emission right generated by the green technology input of the manufacturing enterprise to product 2, that is $\theta_{2}(T)=-\frac{c_{2}^{\prime}\left(T_{2}\right)}{k_{2}^{\prime}\left(T_{2}\right)}$.
Proposition 4 The manufacturing enterprise carries on the carbon emission right transaction and the green technology input combination decision, causes the manufacturing enterprise to maximize the profit the optimal green technology input level and the optimal production combination existence and the unique, the optimal production combination is:

$$
\begin{aligned}
& \quad Q_{i c}^{*}=F^{-1}\left(\frac{p_{i}+r_{i}-c_{i}\left(T_{i c}\right)-w k_{i}\left(T_{i c}\right)}{p_{i}+r_{i}-v_{i}}\right) ; i=1,2 \text { and satisfiy } \\
& \theta_{1}\left(Q_{1 c}^{*}\right)=\theta_{2}\left(Q_{2 c}^{*}\right)=w \text { and } \theta_{1}\left(T_{1 c}^{*}\right)=\theta_{2}\left(T_{2 c}^{*}\right)=w \text { The } \\
& \text { optimal green technology input level is } T_{1 c}^{*} \in(0,1) \text { and } \\
& T_{2 c}^{*} \in(0,1) \text { the volume of carbon emission rights is } \\
& W_{c}^{*}=\sum_{i=1}^{2} k_{i}\left(T_{i}\right) Q_{i}-K .
\end{aligned}
$$

Proposition 4 shows that under the constraint of carbon emissions limits, the optimal decision of manufacturing enterprises to carry out carbon emission permits trade and green technology input combination must meet the condition of $\theta_{1}\left(T_{1 c}^{*}\right)=\theta_{2}\left(T_{2 c}^{*}\right)$. Otherwise, manufacturing enterprises can continue to invest green technology in product 1 or product 2 to obtain higher expected profits. At the same time:

When $\theta_{1}\left(T_{1 c}^{*}\right)=\theta_{2}\left(T_{2 c}^{*}\right)>w$, the unit carbon emission right cost generated by green technology investment was higher than the price of unit carbon emission right in the market. Green technology investment would reduce the expected profits of manufacturing enterprises, and manufacturing enterprises would not invest in green technology. Instead, buy carbon rights in the external carbon emission permits the trade market to carry out production activities.

When $\theta_{1}\left(T_{1 c}^{*}\right)=\theta_{2}\left(T_{2 c}^{*}\right)=w$ the unit carbon emission right cost produced after the green technology investment is equal to the price of the unit carbon emission right in the market, the enterprise may choose or carry on the green technology investment, or carries on the carbon emission right transaction.

When $\theta_{1}\left(T_{1 c}^{*}\right)=\theta_{2}\left(T_{2 c}^{*}\right)<w$, the unit carbon emission right cost after green technology investment is lower than the price of unit carbon emission right in the market. Green technology investment will increase the expected profit of manufacturing enterprises, and manufacturing enterprises will carry out green technology investment. To make more profits.

Therefore, when the unit carbon emission right cost is lower than the unit carbon emission right price in the market, the manufacturing enterprise will choose to invest in green technology. When the unit carbon emission right cost is higher than the unit carbon emission right price in the market, the manufacturing enterprise will choose to make the carbon emission right transaction decision.

Further, after the decision of the manufacturer to choose the trading of carbon emission rights:

The above proof shows that the manufacturing enterprise must meet the condition of $\theta_{1}\left(Q_{1 c}^{*}\right)=\theta_{2}\left(Q_{2 c}^{*}\right)$ under the optimal production decision, otherwise the 
manufacturing enterprise can obtain higher expected profit by producing more products 1 or 2 . At the same time:

When $\theta_{1}\left(Q_{1 c}^{*}\right)=\theta_{2}\left(Q_{2 c}^{*}\right)>w$, the manufacturer of the unit carbon emission right expected the profit to increase higher than the price of the unit carbon emission right, and the manufacturer would buy the carbon emission right to produce more products to obtain more profits.

When $\theta_{1}\left(Q_{1 c}^{*}\right)=\theta_{2}\left(Q_{2 c}^{*}\right)<w$, the manufacturer of the unit's carbon emission right expected the profit to increase less than one unit's carbon emission right price, and the manufacturer would sell the carbon emission right.

When $\theta_{1}\left(Q_{1 c}^{*}\right)=\theta_{2}\left(Q_{2 c}^{*}\right)=w$, the manufacturer expected the profit increase to be equal to the price of one unit of carbon emission right, and the manufacturer would not trade the carbon emission right. In this case, there is an optimal production decision, which makes the enterprise expect the maximum profit.

The following propositions can be further obtained:

\section{Corollary 7}

1. if $\theta\left(Q_{1 K}^{*}\right)=\theta\left(Q_{2 K}^{*}\right)>$, then, $Q_{1 K}^{*}<Q_{1 c}^{*}<Q_{1}^{*} ; Q_{2 K}^{*}<Q_{2 c}^{*}<Q_{2}^{*}$

2. If $\theta\left(Q_{1 K}^{*}\right)=\theta\left(Q_{2 K}^{*}\right)=w$, then, $Q_{1 c}^{*}=Q_{1 K}^{*}<Q_{1}^{*}$; $Q_{2 c}^{*}=Q_{2 K}^{*}<Q_{2}^{*}$.

3. If $\theta\left(Q_{1 K}^{*}\right)=\theta\left(Q_{2 K}^{*}\right)<w$, then, $Q_{1 c}^{*}<Q_{1 K}^{*}<Q_{1}^{*} ; Q_{2 c}^{*}$ $<Q_{2 K}^{*}<Q_{2}^{*}$

Corollary 7 shows that under the carbon emissions limits constraint, the optimal production of the product $i ;(i=1,2)$ after the manufacturing enterprise makes the carbon emission right transaction and the green technology input combination decision is not higher than the optimal production without the carbon emissions limits constraint. The relationship with the optimal production under the carbon emissions limits depends on the profit generated by the increase in unit carbon emission rights.

$$
\begin{aligned}
& \text { Corollary } 8 \text { When } \quad K^{*}=\sum_{i=1}^{2} k_{i}\left(T_{i}\right) Q_{i c}^{*}+\frac{1}{w} \\
& \left(\pi^{n}\left(\mathbf{Q}^{*}\right)-\pi^{c}\left(\mathbf{Q}_{\mathbf{c}}^{*}, \mathbf{T}_{\mathbf{c}}^{*}\right)\right) .
\end{aligned}
$$

1. If $K>K^{*}$, then, $\pi^{c}\left(\mathbf{Q}_{\mathbf{c}}^{*}, \mathbf{T}_{\mathbf{c}}^{*}\right)>\pi^{n}\left(\mathbf{Q}^{*}\right)>\pi^{K}\left(\mathbf{Q}_{\mathbf{K}}^{*}\right)$.

2. If $K=K^{*}$, then, $\pi^{c}\left(\mathbf{Q}_{\mathbf{c}}^{*}, \mathbf{T}_{\mathbf{c}}^{*}\right)=\pi^{n}\left(\mathbf{Q}^{*}\right)>\pi^{K}\left(\mathbf{Q}_{\mathbf{K}}^{*}\right)$.

3. If $K<K^{*}$, then, $\pi^{n}\left(\mathbf{Q}^{*}\right)>\pi^{c}\left(\mathbf{Q}_{\mathbf{c}}^{*}, \mathbf{T}_{\mathbf{c}}^{*}\right) \geq \pi^{K}\left(\mathbf{Q}_{\mathbf{K}}^{*}\right)$.

Corollary 8 shows that under the carbon emissions limits constraint, the maximum expected a profit of the manufacturing enterprise when making the carbon emission right transaction and the green technology input combination decision is not less than the expected profit when there is a carbon emissions limits constraint. Whether the expectation is higher than that under the carbon emissions limits mainly depends on the size of the government's initial carbon quota.

\section{Numerical analysis}

Considering a manufacturing enterprise producing a single product in the free market, the market demand is subject to normal distribution $X \sim N\left(200,50^{2}\right)$. At the end period of the sales process, the remaining inventory will be treated according to the residual value. Meanwhile, manufacturing enterprises will also face shortage losses. The parameters are shown in Table 2.

\subsection{Carbon-free limits and constraints}

Through the solution, under the constraint of no carbon emissions limits, the optimal production capacity of the manufacturing enterprise $Q^{*}=230, \pi^{*}=10143$.

Under the carbon emissions limits constraint, the government sets the carbon emissions limits $K=150$ (unit). By solving, the optimal production capacity of the manufacturing enterprise under the constraint of carbon emissions limits $Q_{K}^{*}=150, \pi_{K}^{*}=7534$.

The comparison between the optimal production and expected profit of the manufacturing enterprise under the condition of unlimited and carbon emissions limits is shown in Fig. 1. Numerical analysis shows that:

Carbon quotas set by:

1. Governments have an impact on manufacturing firms' optimal production decisions;

2. Due to the existence of the carbon emissions limits stipulated by the government, the optimal production capacity of the manufacturing enterprise under the carbon emissions limits constraint is 150 units, the expected profit is 7534 , and the optimal production capacity is 230 units and the expected profit is 10,143 units without the carbon emissions limits constraint. The conclusion shows that the optimal production and expected profit of the manufacturing enterprise will not exceed the optimal production and expected profit under the carbon emissions limits constraint;

3. It can be seen from Fig. 1 that the gap between the expected profit of the manufacturing enterprise under

Table 2 Model parameters

\begin{tabular}{cccccc}
\hline & $p$ & $c$ & $r$ & $v$ & $k$ \\
\hline Value & 100 & 40 & 20 & 10 & 1 \\
\hline
\end{tabular}


the carbon emissions limits constraint and the expected profit under the unlimited situation is the space that the enterprise can improve through the decision optimization such as carbon emission permits trade or green technology input.

\subsection{Carbon emissions trading scenarios}

Under the constraint of carbon emissions limits, manufacturing enterprises make the decision of case one, that is, only carbon emission permits trade. Among them $w$ is the unit carbon emission right price, $W$ is the external carbon emission permits trade market carbon emission right trading volume.

Set $w \in[0,60][0,60]$, study when the unit carbon emission right price $w$ changes in the corresponding range on the manufacturing enterprise optimal production volume, carbon emission right trading volume, and expected profit changes are shown in Table 3 and Fig. 2.

As can be seen from Table 3 and Fig. 2:

1. In the case of carbon emissions limits constraints, carbon emission permits trade by manufacturing enterprises is helpful to optimize manufacturing decisions. It can be seen that most of the expected profits $\pi_{e}^{*}$ in the case of carbon emission permits trade by manufacturing enterprises are between the expected profits $\pi^{*}$ in the case of unlimited constraints and the expected profits $\pi_{K}^{*}$ in the case of carbon emissions limits constraints;

2. The theory is that the unit carbon emission right price $w$ is lower than the marginal profit generated by the increase of the unit carbon emission right of the manufacturing enterprise, the manufacturing enterprise will purchase the carbon emission right. With the decrease of unit carbon emission right price, the optimal produc-

tion volume, as well as the trading volume and expected profit of carbon emission right will increase. When the extreme situation occurs and the price of unit carbon emission right is very low, the manufacturing enterprise will purchase a large amount of carbon emission right, and the optimal production and expected profit are close to the optimal production and expected profit under the condition of no carbon emissions limits.

3. The theory is that the unit carbon emission right price $w$ is higher than the marginal profit generated by the increase of the unit carbon emission right of the manufacturing enterprise, the enterprise will not purchase the carbon emission right.

\subsection{Green technology inputs}

Under the constraint of carbon emissions limits, manufacturing enterprises make two decisions, that is, only green technology input to obtain carbon emission rights savings, disguised to obtain additional carbon emission rights. Let the corresponding functions and parameters be as follows:

$c(T)=c+\frac{1}{2} \alpha T^{2} ; c=40 ; \alpha \in[0,40]$ The greater the elastic coefficient of the increase in unit product cost caused by green technology input $c(T)$, the higher the unit product cost a caused by green technology input.

Table 3 Changes in key parameters in the context of carbon emission permits trade

\begin{tabular}{llll}
\hline$w$ & $W$ & $Q_{e}^{*}$ & $\pi_{e}^{*}$ \\
\hline 10 & 68 & 218 & 9408 \\
20 & 56 & 206 & 8796 \\
30 & 44 & 194 & 8299 \\
40 & 32 & 182 & 7918 \\
50 & 20 & 170 & 7659 \\
60 & 4 & 154 & 7539 \\
\hline
\end{tabular}

Fig. 1 Expected profits of manufacturing enterprises under carbon emissions limits

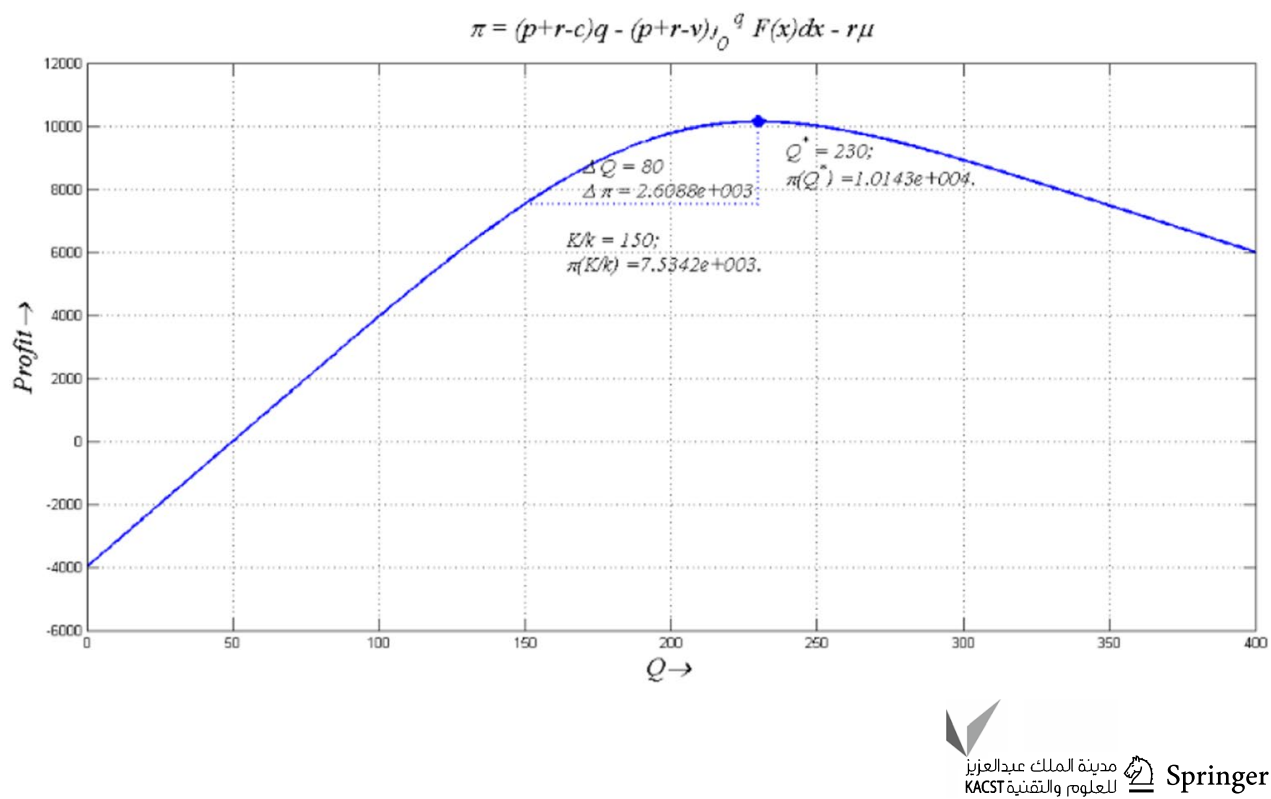


Fig. 2 Expected profits of manufacturing enterprises in the case of carbon emission permits trade

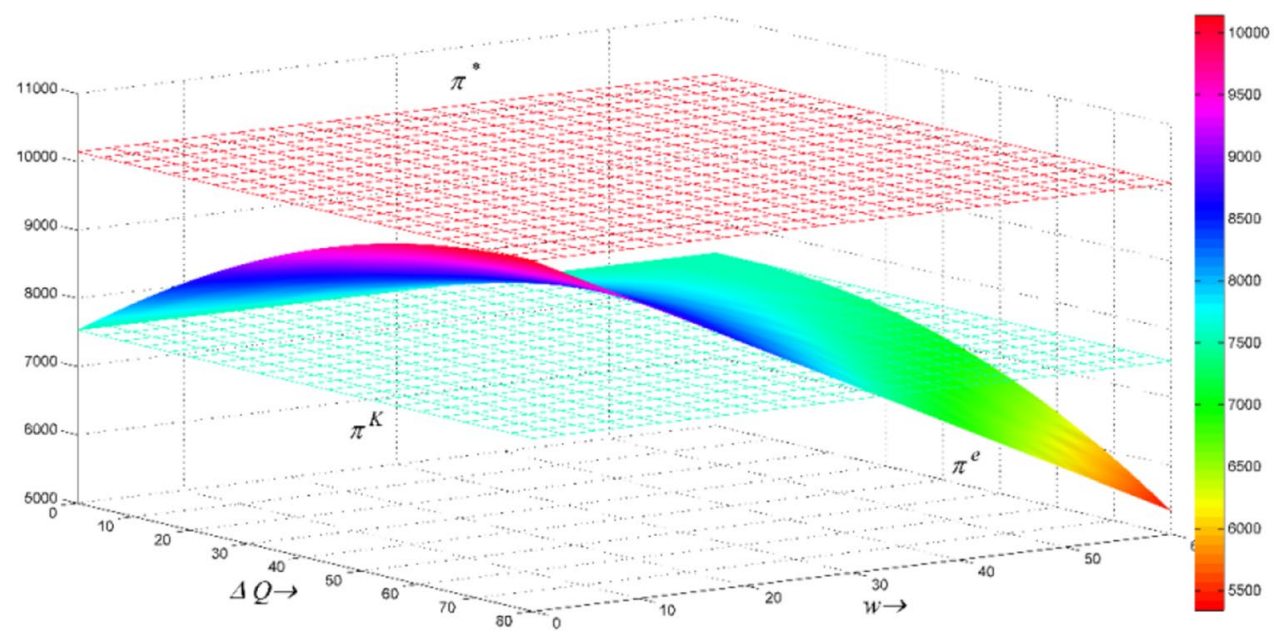

$k(T)=k-\beta T ; \beta=[0.0 .4]$ The greater the coefficient of elasticity $\boldsymbol{\beta}$ that green technology inputs lead to the reduction of carbon emissions per unit product, the better the effect of green technology in reducing carbon emissions per unit product.

Set $\alpha \in[0,40], \beta=[0.0 .4]$.

When $\alpha$ and $\beta$ in the corresponding interval changes on the manufacturing enterprise optimal green technology input level, optimal production and expected profit changes are shown in Table 4 and Figs. 3, 4, 5, which $(\cdot)=\left(T^{*} ; Q_{t}^{*} ; \pi_{t}^{*}\right)$.

As can be seen from Table 4 and Figs. 3, 4, 5.

1. In the case of carbon emissions limits constraint, the green technology investment of manufacturing enterprises is helpful to optimize the production decision of manufacturing enterprises. It can be seen that most of the expected profits $\pi^{t}$ of manufacturing enterprises in the case of green technology investment are above the expected profits $\pi^{K}$ in the case of carbon emissions limits constraints.

2. It is determined that the level of green technology input to reduce unit carbon emissions $\beta$ is certain. With the increase of green technology input level a, the profit of enterprises will increase first and then decrease gradually, and there is an optimal level of green technology input. With the increase, that is, the unit product cost caused by green technology investment increases, the profit of the enterprise will continue to decline.
3. When a is determined, that is, the unit product cost caused by green technology investment is certain. With the increase of green technology investment, the enterprise profit will increase first and then decrease gradually, and there is an optimal green technology investment level. With the increase of green technology investment $\beta$, the better the effect of reducing unit carbon emissions, the profits of enterprises will continue to increase.

4. when green technology investment is certain, with the increase $\beta$, that is, the better the effect of green technology investment to reduce unit carbon emissions, the profits of enterprises will continue to increase. With the increase a, that is, the unit product cost caused by green technology investment increases, the profit of the enterprise will continue to decline.

The above analysis shows that the level of green technology, such as low carbon emission reduction, on the one hand, determines the effect of carbon emission reduction, on the other hand, under the carbon quota and trading mechanism, Enterprises with core low-carbon emission reduction technology will have a competitive advantage in reducing carbon emissions and obtaining greater profits.

\subsection{Joint decision-making on carbon emissions trading and green technology inputs}

Under the constraint of carbon emissions limits, manufacturing enterprises make three decisions, that is, the combination
Table 4 Changes in main parameters in the case of green technology input

\begin{tabular}{lllll}
\hline $\mathrm{a} \beta$ & 0.1 & 0.2 & 0.3 & 0.4 \\
\hline 10 & $(0.62 ; 159 ; 7838)$ & $(0.9 ; 183 ; 8532)$ & $(0.82 ; 199 ; 9139)$ & $(0.72 ; 211 ; 9495)$ \\
20 & $(0.32 ; 155 ; 7697)$ & $(0.56 ; 169 ; 8103)$ & $(0.6 ; 183 ; 8614)$ & $(0.64 ; 202 ; 9031)$ \\
30 & $(0.18 ; 153 ; 7643)$ & $(0.34 ; 161 ; 7925)$ & $(0.54 ; 179 ; 8328)$ & $(0.5 ; 188 ; 8726)$ \\
40 & $(0.18 ; 158 ; 7619)$ & $(0.28 ; 159 ; 7837)$ & $(0.42 ; 172 ; 8153)$ & $(0.46 ; 184 ; 8526)$ \\
\hline
\end{tabular}


Fig. 3 Changes in green technology inputs and expected profits $\alpha T$

Fig. 4 Changes in green technology inputs and expected profits $\beta T$

Fig. 5 Changes in green technology inputs and expected profits $\alpha \beta$
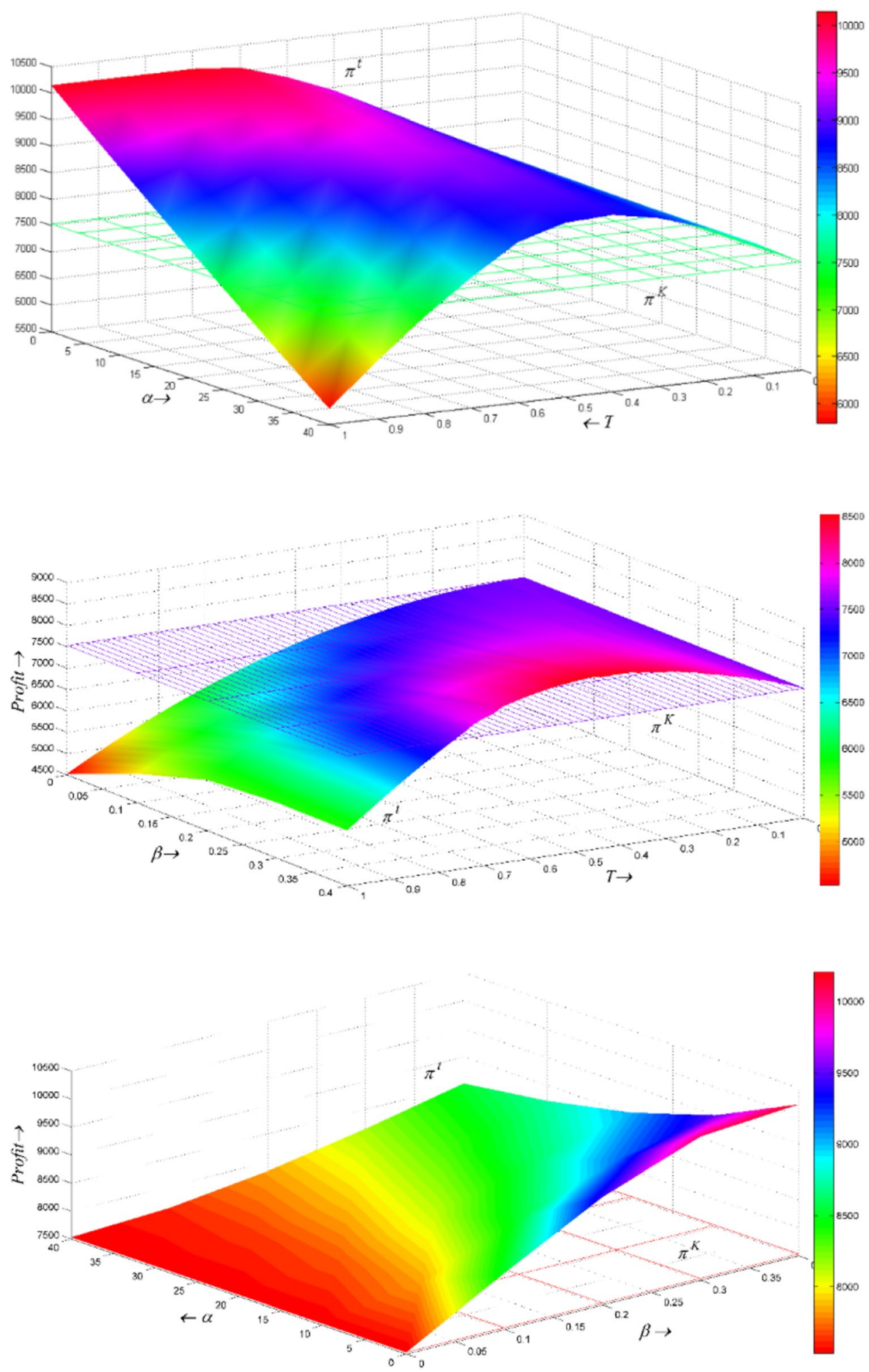

decision of carbon emission permits trade and green technology input. Let the corresponding functions and parameters be as follows:

$$
\begin{aligned}
& c(T)=c+\frac{1}{2} \alpha T^{2} ; c=40, \alpha \in[0,40] ; \\
& k(T)=k-\beta T ; \beta \in[0,0.4] ; w \in[0,60] .
\end{aligned}
$$


Set $w \in[0,60] \alpha \in[0,40] \beta \in[0,0.4]$. when $w, \alpha$ and $\beta$ are the effects of changes in the corresponding interval on the optimal green technology input level, optimal production, expected profit and carbon emission permits trade volume of manufacturing enterprises are shown in Table 5 and Fig. 6, in which $w(\cdot)=\left(T_{c}^{*}, Q_{c}^{*}, \pi_{c}^{*}, W_{c}^{*}\right)$.

As can be seen from Tables 5 and Fig. 6:

1. When $w$ is determined, that is, the unit carbon emission price is certain, with the increase $\alpha$, that is, the unit product cost caused by the green technology input increases, the profit of the enterprise will continue to decline. With the increase $\beta$, that is, the better the level of green technology to reduce unit carbon emissions, the more profits increase.

2. When $\alpha$ is determined, that is, the unit product cost caused by green technology input is certain. With the increase of $w$ unit carbon emission price, the profit of the enterprise will increase first and then decrease. With the increase $\beta$, that is, the better the level of green technology to reduce unit carbon emissions, the profits of enterprises will continue to increase.

3. When $\beta$ is determined that green technology reduces the level of unit carbon emissions, with the increase $\alpha$, that is, the unit product cost caused by green technology investment increases, the profits of enterprises will continue to decline. With the increase, that is, the unit carbon emission price increases, the profit of the enterprise will increase first and then decrease.

The above analysis can further confirm that the effect of green technology on reducing unit carbon emission rights has a very important impact on enterprise profits; The price of carbon emission rights in the external carbon emission permits trade market will affect the trading volume and expected profit of carbon emission rights.

Set $w=30 \alpha=40 \beta=0.2$ When $T$ is the change in the corresponding interval affects the optimal production and expected profit of the manufacturing enterprise, see Fig. 6 . Figure 7 shows:

In the case of carbon emissions limits constraint, the manufacturing enterprise makes three decisions. Under the given parameters, there is a green technology input level, production volume and expected profit that maximizes the expected profit of the manufacturing enterprise.

\section{Conclusions}

This paper studied the production decision system of manufacturing enterprises under the constraints of carbon emission reduction policy. The analysis showed that the carbon emissions limits set by the government have an important impact on the optimal production decision of the manufacturing enterprise, and the production decision of the

Table 5 Changes in main parameters in the case of green technology input

\begin{tabular}{|c|c|c|c|c|c|c|}
\hline \multirow{2}{*}{$\begin{array}{l}w \\
\alpha \beta\end{array}$} & \multicolumn{2}{|l|}{20} & \multicolumn{2}{|l|}{40} & \multicolumn{2}{|l|}{60} \\
\hline & 0.2 & 0.4 & 0.2 & 0.4 & 0.2 & 0.4 \\
\hline 10 & $(0.1 ; 206 ; 8868 ; 52)$ & $(0.1 ; 206 ; 8951 ; 48)$ & $(0.1 ; 183 ; 8056 ; 29)$ & $(0.1 ; 184 ; 8203 ; 27)$ & $(0.1 ; 156 ; 7718 ; 3)$ & $(0.1 ; 158 ; 7906 ; 2)$ \\
\hline 20 & $(0.1 ; 206 ; 8858 ; 52)$ & $(0.1 ; 206 ; 8941 ; 48)$ & $(0.1 ; 183 ; 8047 ; 29)$ & $(0.1 ; 184 ; 8193 ; 27)$ & $(0.1 ; 156 ; 7710 ; 3)$ & $(0.1 ; 158 ; 7898 ; 2)$ \\
\hline 30 & $(0.1 ; 205 ; 8848 ; 51)$ & $(0.1 ; 206 ; 8930 ; 48)$ & $(0.1 ; 183 ; 8037 ; 29)$ & $(0.1 ; 184 ; 8184 ; 27)$ & $(0.1 ; 156 ; 7702 ; 3)$ & $(0.1 ; 158 ; 7890 ; 2)$ \\
\hline 40 & $(0.1 ; 205 ; 8837 ; 51)$ & $(0.1 ; 206 ; 8920 ; 48)$ & $(0.1 ; 183 ; 8028 ; 29)$ & $(0.1 ; 184 ; 8175 ; 27)$ & $(0.1 ; 156 ; 7694 ; 3)$ & $(0.1 ; 158 ; 7882 ; 2)$ \\
\hline
\end{tabular}

Fig. 6 Carbon emission permits trade and green technology investment portfolio decision making, $\alpha \beta T$ and expected profits

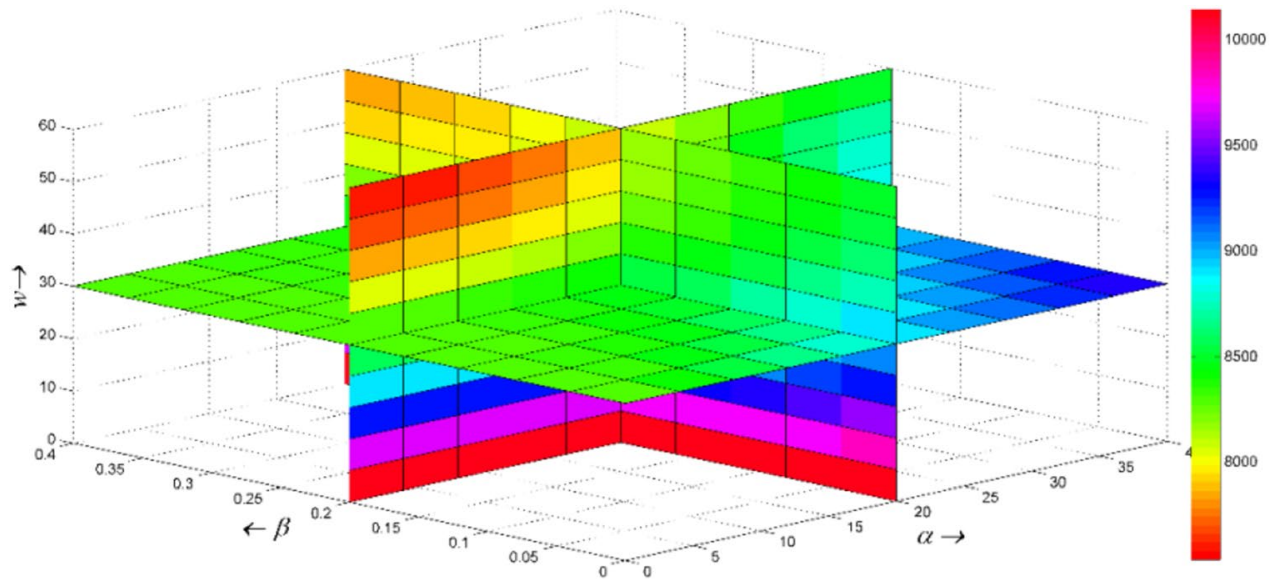


manufacturing enterprise would be optimized and improved to a certain extent by considering the carbon emission rights trading and the green technology investment. Nevertheless, the following suggestions limitations need to be noticed.

First, carbon emission permits trade can give manufacturers more flexibility and increase their profits. However, when trading carbon emission rights is higher than (equal to, lower than) the profit, and the carbon emissions limits is limited by government, the maximum expected profit of the manufacturing enterprise depends on the carbon quota given by the government to the manufacturing enterprise at the beginning of the period.

Therefore, it is an important task for the government to set the initial carbon quota scientifically and reasonably. The scientific and reasonable formulation of the initial carbon quota would mobilize the enthusiasm and initiative of manufacturing enterprises to participate in carbon emission reduction, not only to reduce carbon dioxide $\left(\mathrm{CO}_{2}\right)$ emissions, but also not to reduce the overall social welfare. If the initial carbon quota is unreasonable, for example, the quota is too high, it would not reduce carbon dioxide $\left(\mathrm{CO}_{2}\right)$ emissions.

Second, the condition for manufacturing enterprises to invest in carbon emission reduction technology is that the marginal cost of unit carbon emission right after green technology investment is lower than the price of unit carbon emission right in the market. Furthermore, the willingness of the enterprise to invest in carbon emission reduction technology would increasing, if the effect of green technology investment in reducing unit carbon emissions is getting better, the among of carbon dioxide $\left(\mathrm{CO}_{2}\right)$ is reducing, while the enterprise profits are increasing. As a result, on one hand, the government should guide the formulation and formation of carbon emission permits trade mechanism, especially the price formation mechanism of carbon emission rights. On the other hand, to encourage manufacturing enterprises to develop carbon emission reduction technology, to improve the effect of carbon emission reduction technology to reduce carbon dioxide $\left(\mathrm{CO}_{2}\right)$ emissions, to promote enterprises with core low carbon emission reduction technology to form greater carbon emission reduction ability, and to form a competitive advantage for the enterprises eventually. Even though the corresponding international rules, carbon emission reduction technology would output.

Third, by considering constraints of carbon emission reduction policy, when the optimal production of enterprises is constrained by carbon quota, the enterprise' decision on whether to choose carbon emission permits trade, or to choose green technology input, or the combination of carbon emission permits trade with green technology investment, which related to its development stage and surrounding environment, as well as the resources and low carbon emission reduction technology it had. When the manufacturing enterprise is in a growing stage of development, or it has fewer resources, or its ability to master low-carbon emission reduction technologies is limited, the enterprise's decision-making may be more tend to the immediate interests of reality, in other words, the enterprise more tend to choose the decision-making of carbon emission right trading under the constraints of carbon emissions limits. When the manufacturing enterprise is in a mature stage of development, or it has more resources, or it has a strong ability to master low-carbon emission reduction technology, in short, the enterprise is more willing to consider the issue of enterprise development from a long-term sustainable perspective. In other words, the enterprise's production decision-making more tends to choose green technology input decisionmaking. When the development stage of the manufacturing enterprise is between growth and maturity, or the ability of the enterprise to master the resources and low carbon emission reduction technology is in the middle level, the enterprise's decision-making on the production trend to the way of combining the two decisions discussed above.
Fig. 7 Expected profit of a manufacturer under given parameters

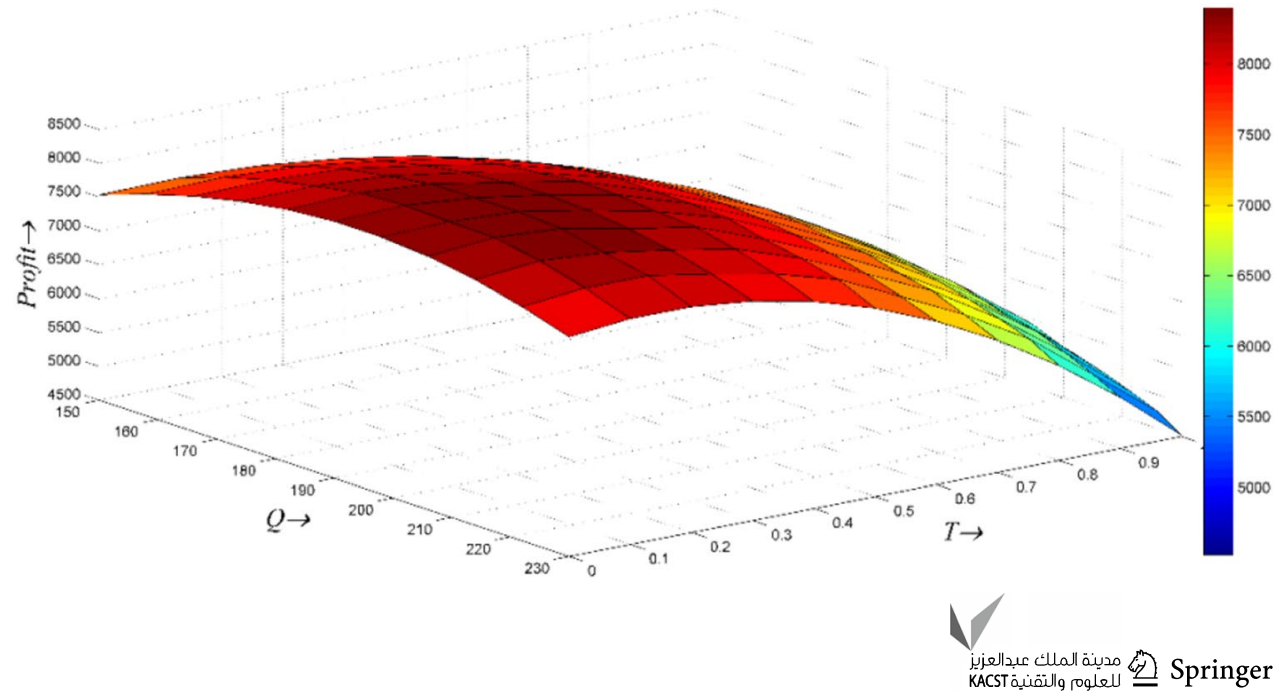




\section{Appendix}

\section{Proposition 1 proves that:}

Construct the Lagrange function:

$$
\begin{aligned}
L^{K}\left(\mathbf{Q}_{\mathbf{K}}, \lambda\right)= & \sum_{i=1}^{2}\left(\left(p_{i}+r_{i}-c_{i}\right) Q_{i K}-\left(p_{i}+r_{i}-v_{i}\right) \int_{0}^{Q_{i K}} F_{i}(x) d x-r_{i} \mu_{i}\right) \\
& +\lambda\left(K-\sum_{i=1}^{2} k_{i} Q_{i K}\right) .
\end{aligned}
$$

The condition of $K-T$ is: (Condition 1 )

$$
\begin{aligned}
\frac{\partial L^{K}\left(\mathbf{Q}_{\mathbf{K}}, \lambda\right)_{Q_{i K}}}{\partial Q_{i K}}= & \left(p_{i}+r_{i}-c_{i}\right)-\left(p_{i}+r_{i}-v_{i}\right) F_{i}\left(Q_{i K}\right) \\
& -\lambda k_{i} \leq 0 Q_{i} \geq 0 Q_{i} \frac{\partial L^{K}\left(\mathbf{Q}_{\mathbf{K}}, \lambda\right)_{Q_{i K}}}{\partial Q_{i K}}=0 .
\end{aligned}
$$

(Condition 2)

$\frac{\partial L^{K}\left(\mathbf{Q}_{\mathbf{K}}, \lambda\right)_{\lambda}}{\partial \lambda}=K-\sum_{i=1}^{2} k_{i} Q_{i K} \geq 0 \lambda \geq 0 \lambda \frac{\partial L^{K}\left(\mathbf{Q}_{\mathbf{K}}, \lambda\right)_{\lambda}}{\partial \lambda}=0$

Because this article discusses manufacturing enterprises produce two kinds of products, therefore, $Q_{1 k}, Q_{2 k}>0$.

The above condition is $\lambda=0, K-T$ can be transformed into:

$\left(p_{i}+r_{i}-c_{i}\right)-\left(p_{i}+r_{i}-v_{i}\right) F_{i}\left(Q_{i k}\right)=0$ The solution is: $Q_{i K}^{*}=F^{-1}\left(\frac{p_{i}+r_{i}-c_{i}}{p_{i}+r_{i}-v_{i}}\right) ; i=1,2$..

The above condition is $\lambda \neq 0, K-T$ can be transformed into:

$$
\left\{\begin{array}{l}
\left(p_{i}+r_{i}-c_{i}\right)-\left(p_{i}+r_{i}-v_{i}\right) F_{i}\left(Q_{i K}\right)-\lambda k_{i}=0 ; i=1,2 \\
K-\sum_{i=1}^{2} k_{i} Q_{i K}=0
\end{array} .\right.
$$

Because the problem is concave planning, the above equations are established under the condition of $Q_{1 K}^{*} Q_{2 K}^{*} \lambda_{K}^{*}$.

Under the optimal output obtained from (1), the production decision of the manufacturing enterprise degenerates to the production decision without carbon emissions limits constraint.

$\lambda$ Under the optimal output obtained from (2), because of $\lambda \neq 0$, and therefore $Q_{i K}^{*}<Q_{i}^{*} ; i=1,2$, and $K-\sum_{i=1}^{2} k_{i} Q_{i K}^{*}=0$, in which $Q_{1 K}^{*} Q_{2 K}^{*} \lambda_{K}^{*}$ is a point of $K-T$. In addition, the income generated by increasing the unit carbon emission right input on behalf of the manufacturing enterprise in the optimal output, the optimal production decision of the manufacturing enterprise was limited to the carbon emissions limits when $\lambda \neq 0$. As a result:

$\theta_{1}\left(Q_{1 K}\right)=\frac{1}{k_{1}}\left(\left(p_{1}+r_{1}-c_{1}\right)-\left(p_{1}+r_{1}-v_{1}\right) F_{1}\left(Q_{1 K}\right)\right)$
$\theta_{2}\left(Q_{2 K}\right)=\frac{1}{k_{2}}\left(\left(p_{2}+r_{2}-c_{2}\right)-\left(p_{2}+r_{2}-v_{2}\right) F_{2}\left(Q_{2 K}\right)\right)$

The manufacturing enterprise produces two products, $\theta_{1}\left(Q_{1 K}^{*}\right)=\theta_{2}\left(Q_{2 K}^{*}\right)$ indicates that the profit generated by the unit carbon emission right of product 1 and product 2 must be equal. Otherwise, if $\theta_{1}\left(Q_{1 K}^{*}\right)>\theta_{2}\left(Q_{2 K}^{*}\right)$, produce one more unit of product 1 can make more profits, and because of $\frac{\partial^{2} \pi^{K}\left(\mathbf{Q}_{\mathbf{K}}\right)_{Q_{i}}}{\partial Q_{1 K}^{2}}<0, \theta_{1}\left(Q_{1 K}^{*}\right)$ will continue to decrease and the manufacturer will continue to produce product 1 until equilibrium $\theta_{1}\left(Q_{1 K}^{*}\right)=\theta_{2}\left(Q_{2 K}^{*}\right)$ occurs. The same can be analyzed $\theta_{1}\left(Q_{1 K}^{*}\right)<\theta_{2}\left(Q_{2 K}^{*}\right)$. The certificate is over.

Corollary 1 proves that:

The Lagrangian factor can be obtained from the constraint condition of formula $1: \varphi \geq 0$

$\left\{\begin{array}{l}k_{1} Q_{1}+k_{2} Q_{2}-K \leq 0 \\ \varphi\left(k_{1} Q_{1}+k_{2} Q_{2}-K\right)=0 \\ \left(p_{1}+r_{1}-c_{1}\right)-\left(p_{1}+r_{1}-v_{1}\right) F_{1}\left(Q_{1}\right)-\varphi k_{1}=0 \\ \left(p_{2}+r_{2}-c_{2}\right)-\left(p_{2}+r_{2}-v_{2}\right) F_{2}\left(Q_{2}\right)-\varphi k_{2}=0\end{array}\right.$.

When $\varphi=0$, At that time, you can get: $\frac{\partial \pi^{n}\left(Q_{1}, Q_{2}\right)}{\partial Q_{1}}=0$ $\frac{\partial \pi^{n}\left(Q_{1}, Q_{2}\right)}{\partial Q_{2}}=0$.

Therefore, we can get, at this time, $Q_{1 K}^{*}=Q_{1}^{*} Q_{2 K}^{*}=Q_{2}^{*}$ $k_{1} Q_{1}^{*}+k_{2} Q_{2}^{*} \leq K$.

When $\varphi>0$, At that time, you could:

$\frac{\partial \pi^{n}\left(Q_{1}, Q_{2}\right)}{\partial Q_{1}}=\left(v_{1}-p_{1}-r_{1}\right) F_{1}\left(Q_{1}\right)+p_{1}+r_{1}-c_{1}=\varphi k_{1}>0$.

$\frac{\partial \pi^{n}\left(Q_{1}, Q_{2}\right)}{\partial Q_{2}}=\left(v_{2}-p_{2}-r_{2}\right) F_{2}\left(Q_{2}\right)+p_{2}+r_{2}-c_{2}=\varphi k_{2}>0$.

From this we can get, at this time, $Q_{1}^{K}<Q_{1}^{*} Q_{2}^{K}<Q_{2}^{*}$ $k_{1} Q_{1}^{*}+k_{2} Q_{2}^{*}=K$.

Combined, $Q_{1}^{K} \leq Q_{1}^{*} Q_{2}^{K} \leq Q_{2}^{*}$.

The certificate is over.

Corollary 2 proves that:

From Proposition 1 and Corollary 1, we can find:

$k_{1} Q_{1}^{*}+k_{2} Q_{2}^{*} \leq K Q_{1 K}^{*}=Q_{1}^{*}, Q_{2 K}^{*}=Q_{2}^{*}$.

At the time, then, you can get: $\pi^{K}\left(Q_{1 K}^{*}, Q_{2 K}^{*}\right)=\pi^{n}\left(Q_{1}^{*}, Q_{2}^{*}\right)$

$k_{1} Q_{1}^{*}+k_{2} Q_{2}^{*}>K, Q_{1 K}^{*}<Q_{1}^{*}, Q_{2 K}^{*}<Q_{2}^{*}$.

At the time, then, you can get: $\pi^{K}\left(Q_{1 K}^{*}, Q_{2 K}^{*}\right)=\pi^{n}\left(Q_{1 K}^{*}, Q_{2 K}^{*}\right)<\pi^{n}\left(Q_{1}^{*}, Q_{2}^{*}\right)$.

The certificate is over.

Proposition 2 proves that: 
$W=\sum_{i=1}^{2} k_{i} Q_{i e}-K$. According to Formula (4), the expected profit function of a manufacturing enterprise is:

$$
\begin{aligned}
\pi^{e}\left(\mathbf{Q}_{\mathbf{e}}\right)= & \sum_{i=1}^{2} \pi^{e}\left(Q_{i e}\right) \\
= & \sum_{i=1}^{2}\left(\left(p_{i}+r_{i}-c_{i}\right) Q_{i e}-\left(p_{i}+r_{i}-v_{i}\right) \int_{0}^{Q_{i e}} F_{i}(x) d x-r_{i} \mu_{i}\right) \\
& \quad-w\left(\sum_{i=1}^{2} k_{i} Q_{i e}-K\right) .
\end{aligned}
$$

$\pi^{e}\left(\mathbf{Q}_{\mathbf{e}}\right) Q_{i e} ; i=1,2$ For the first order partial derivation:

$$
\frac{\partial \pi^{e}(\mathbf{Q})_{Q_{i e}}}{\partial Q_{1 e}}=\left(p_{1}+r_{1}-c_{1}\right)-\left(p_{1}+r_{1}-v_{1}\right) F\left(Q_{1 e}\right)-w k_{1} .
$$

$\frac{\partial \pi^{e}\left(\mathbf{Q}_{\mathbf{e}}\right)_{Q_{i e}}}{\partial Q_{2 e}}=\left(p_{2}+r_{2}-c_{2}\right)-\left(p_{2}+r_{2}-v_{2}\right) F\left(Q_{2 e}\right)-w k_{2}$.

$\pi^{e}\left(\mathbf{Q}_{\mathbf{e}}\right) Q_{i e} ; i=1,2$ The second order partial derivation is obtained:

$\frac{\partial^{2} \pi^{e}\left(\mathbf{Q}_{\mathbf{e}}\right)_{Q_{i e}}}{\partial Q_{1 e}^{2}}=-\left(p_{1}+r_{1}-v_{1}\right) f\left(Q_{1 e}\right)<0$.

$\frac{\partial^{2} \pi^{e}\left(\mathbf{Q}_{\mathbf{e}}\right)_{Q_{i e}}}{\partial Q_{2 e}^{2}}=-\left(p_{2}+r_{2}-v_{2}\right) f\left(Q_{2}\right)<0$.

$\frac{\partial^{2} \pi^{e}\left(\mathbf{Q}_{\mathbf{e}}\right)_{Q_{i e}}}{\partial Q_{1 e} \partial Q_{2 e}}=\frac{\partial^{2} \pi^{e}\left(\mathbf{Q}_{\mathbf{e}}\right)_{Q_{i e}}}{\partial Q_{2 e} \partial Q_{1 e}}=0$.

Further to the Hessian matrix:

$$
\begin{aligned}
& \left|\begin{array}{ll}
\frac{\partial^{2} \pi^{e}\left(\mathbf{Q}_{\mathbf{e}}\right)_{Q_{i e}}}{\partial Q_{1 e}^{2}} & \frac{\partial^{2} \pi^{e}\left(\mathbf{Q}_{\mathbf{e}}\right)_{Q_{i e}}}{\partial Q_{1 e} Q_{2 e}} \\
\frac{\partial^{2} \pi^{e}\left(\mathbf{Q}_{\mathbf{e}}\right)_{Q_{i e}}}{\partial Q_{2 e} Q_{1 e}} & \frac{\partial^{2} \pi^{e}\left(\mathbf{Q}_{\mathbf{e}}\right)_{Q_{i e}}}{\partial Q_{2 e}^{2}}
\end{array}\right| \\
& \quad=\left(v_{1}-p_{1}-r_{1}\right) f_{1}\left(Q_{1 e}\right)\left(v_{2}-p_{2}-r_{2}\right) f_{2}\left(Q_{2 e}\right)>0 .
\end{aligned}
$$

$\pi^{e}\left(\mathbf{Q}_{\mathbf{e}}\right) Q_{1} Q_{2} i$ It can be seen that the optimal production of the product is obtained by the concave function of the sum:

$Q_{i e}^{*}=F^{-1}\left(\frac{p_{i}+r_{i}-c_{i}-k_{i} w}{p_{i}+r_{i}-v_{i}}\right) ; i=1,2$.

$$
\begin{aligned}
& \frac{\partial \pi^{e}\left(\mathbf{Q}_{\mathbf{e}}\right)_{Q_{i e}}}{\partial{ }^{e}}=0 \text { Order, you can draw: } \\
& \frac{\partial \pi^{e}\left(Q_{\mathbf{e}}\right)_{Q_{i e}}}{\partial Q_{1 e}}=\left(p_{1}+r_{1}-c_{1}\right)-\left(p_{1}+r_{1}-v_{1}\right) F\left(Q_{1 e}\right)=w k_{1} \text { from }
\end{aligned}
$$

which it may be obtained; $\theta_{1}\left(Q_{1 e}^{*}\right)=w$.

$$
\frac{\partial \pi^{e}\left(\mathbf{Q}_{\mathbf{e}}\right)_{Q_{i e}}}{\partial Q_{2 e}}=0 \text { Order, you can draw: }
$$

$\frac{\partial \pi^{e}\left(\mathbf{Q}_{\mathbf{e}}\right)_{Q_{i e}}}{\partial Q_{2 e}}=\left(p_{2}+r_{2}-c_{2}\right)-\left(p_{2}+r_{2}-v_{2}\right) F\left(Q_{2 e}\right)=w k_{2}$ from which it may be obtained; $\theta_{2}\left(Q_{2 e}^{*}\right)=w$. and $\theta_{1}\left(Q_{1 e}^{*}\right)=\theta_{2}\left(Q_{2 e}^{*}\right)=w$.

Carbon emission rights trading volume is. $W_{e}^{*}=\sum_{i=1}^{2} k_{i} Q_{i e}^{*}-K$.

The certificate is over.

Corollary 3 proves that:

$\theta_{i}\left(Q_{i}\right) ; i=1,2 Q_{i} ; i=1,2 Q_{2}$ It is about the decreasing function of Propositions 1 and $2 . \theta_{1}\left(Q_{1}^{*}\right)=0 \theta_{2}\left(Q_{2}^{*}\right)=0$ $\theta_{1}\left(Q_{1 e}^{*}\right)=\theta_{2}\left(Q_{2 e}^{*}\right)=w Q_{1}^{*}>Q_{1 e}^{*} Q_{2}^{*}>Q_{2 e}^{*}$.

$\theta_{1}\left(Q_{1 K}^{*}\right)=\theta_{2}\left(Q_{2 K}^{*}\right)=w$ (1) If so, it can be obtained, $\theta_{1}\left(Q_{1 K}^{*}\right)=\theta_{2}\left(Q_{2 K}^{*}\right)=\theta_{1}\left(Q_{1 e}^{*}\right)=\theta_{2}\left(Q_{2 e}^{*}\right) Q_{1 K}^{*}=Q_{1 e}^{*}<Q_{1}^{*}$ $Q_{2 K}^{*}=Q_{2 e}^{*}<Q_{2}^{*}$.

$\theta_{1}\left(Q_{1 K}^{*}\right)=\theta_{2}\left(Q_{2 K}^{*}\right)<w \quad$ ( 2 ) I f $\quad$ s o , $\theta_{1}\left(Q_{1 K}^{*}\right)=\theta_{2}\left(Q_{2 K}^{*}\right)<\theta_{1}\left(Q_{1 e}^{*}\right)=\theta_{2}\left(Q_{2 e}^{*}\right) Q_{1 e}^{*}<Q_{1 K}^{*}<Q_{1}^{*}$ $Q_{2 e}^{*}<Q_{2 K}^{*}<Q_{2}^{*}$.

$\theta_{1}\left(Q_{1 K}^{*}\right)=\theta_{2}\left(Q_{2 K}^{*}\right)>w \quad$ ( 3 ) I f $\quad$ s o , $\theta_{1}\left(Q_{1 K}^{*}\right)=\theta_{2}\left(Q_{2 K}^{*}\right)>\theta_{1}\left(Q_{1 e}^{*}\right)=\theta_{2}\left(Q_{2 e}^{*}\right) Q_{1 K}^{*}<Q_{1 e}^{*}<Q_{1}^{*}$ $Q_{2 K}^{*}<Q_{2 e}^{*}<Q_{2}^{*}$.

The certificate is over.

Corollary 4 proves that:

$\pi^{e}\left(Q_{1}, Q_{2}\right)$ The maximum value of consideration, yes. $\pi^{e}\left(Q_{1 e}^{*}, Q_{2 e}^{*}\right)>\pi^{n}\left(Q_{1}^{*}, Q_{2}^{*}\right)-w\left(k_{1} Q_{1}^{*}+k_{2} Q_{2}^{*}-K\right)$.

$K \geq k_{1} Q_{1}^{*}+k_{2} Q_{2}^{*}$ If, in this case, so,. Therefore,. If, in this case, considering the maxima, we can see from Corollary 2 that we can get, so,. Comb i n e d i n c o m e , $\pi^{K}\left(Q_{1 K}^{*}, Q_{2 K}^{*}\right)=\pi^{n}\left(Q_{1}^{*}, Q_{2}^{*}\right)$ $\pi^{e}\left(Q_{1 e}^{*}, Q_{2 e}^{*}\right)-\pi^{K}\left(Q_{1 K}^{*}, Q_{2 K}^{*}\right)>-w\left(k_{1} Q_{1}^{*}+k_{2} Q_{2}^{*}-K\right)>0$ $\pi^{e}\left(Q_{1 e}^{*}, Q_{2 e}^{*}\right)>\pi^{K}\left(Q_{1 K}^{*}, Q_{2 K}^{*}\right)$

$K<k_{1} Q_{1}^{*}+k_{2} Q_{2}^{*} \quad K=k_{1} Q_{1 K}^{*}+k_{2} Q_{2 K}^{*} \quad \pi^{e}\left(Q_{e}^{*}\right)$ $\pi^{e}\left(Q_{1 e}^{*}, Q_{2 e}^{*}\right) \geq \pi^{n}\left(Q_{1}^{*}, Q_{2}^{*}\right)-w\left(k_{1} Q_{1}^{*}+k_{2} Q_{2}^{*}-K\right)$ $\pi^{K}\left(Q_{1 K}^{*}, Q_{2 K}^{*}\right)=\pi^{n}\left(Q_{1 K}^{*}, Q_{2 K}^{*}\right)$ $\pi^{e}\left(Q_{1 e}^{*}, Q_{2 e}^{*}\right)-\pi^{K}\left(Q_{1 K}^{*}, Q_{2 K}^{*}\right) \geq-w\left(k_{1} Q_{1 K}^{*}+k_{2} Q_{2 K}^{*}-K\right)=0$ $\pi^{e}\left(Q_{1 e}^{*}, Q_{2 e}^{*}\right)=\pi^{K}\left(Q_{1 K}^{*}, Q_{2 K}^{*}\right) \pi^{e}\left(Q_{1 e}^{*}, Q_{2 e}^{*}\right) \geq \pi^{K}\left(Q_{1 K}^{*}, Q_{2 K}^{*}\right)$

$K \leq k_{1} Q_{1 e}^{*}+k_{2} Q_{2 e}^{*}$ If time, because, so. If the time, therefore, $\pi^{e}\left(Q_{1 e}^{*}, Q_{2 e}^{*}\right)=\pi^{n}\left(Q_{1 e}^{*}, Q_{2 e}^{*}\right)-w\left(k_{1} Q_{1 e}^{*}+k_{2} Q_{2 e}^{*}-K\right) \leq \pi^{n}\left(Q_{1 e}^{*}, Q_{2 e}^{*}\right)<\pi^{n}\left(Q_{1}^{*}, Q_{2}^{*}\right)$ $\pi^{e}\left(Q_{1 e}^{*}, Q_{2 e}^{*}\right)<\pi^{n}\left(Q_{1}^{*}, Q_{2}^{*}\right) \quad K>k_{1} Q_{1 e}^{*}+k_{2} Q_{2 e}^{*}$ $\pi^{e}\left(Q_{1 e}^{*}, Q_{2 e}^{*}\right)>\pi^{n}\left(Q_{1}^{*}, Q_{2}^{*}\right)-w\left(k_{1} Q_{1}^{*}+k_{2} Q_{2}^{*}-K\right)>\pi^{n}\left(Q_{1}^{*}, Q_{2}^{*}\right)$ $\pi^{e}\left(Q_{1 e}^{*}, Q_{2 e}^{*}\right)>\pi^{n}\left(Q_{1}^{*}, Q_{2}^{*}\right)$.

$K^{*} \in\left(k_{1} Q_{1 e}^{*}+k_{2} Q_{2 e}^{*}, k_{1} Q_{1}^{*}+k_{2} Q_{2}^{*}\right)$ Therefore, according to the intermediate value theorem, there is a satisfaction. Reverse solution:

$$
\begin{aligned}
K^{*} \pi^{e}\left(Q_{1 e}^{*}, Q_{2 e}^{*}\right) & =\pi^{n}\left(Q_{1}^{*}, Q_{2}^{*}\right) K^{*} \\
& =k_{1} Q_{1 e}^{*}+k_{2} Q_{2 e}^{*}+\frac{1}{w}\left(\pi^{n}\left(Q_{1}^{*}, Q_{2}^{*}\right)-\pi^{e}\left(Q_{1 e}^{*}, Q_{2 e}^{*}\right)\right) .
\end{aligned}
$$

$\pi^{e}\left(Q_{1}, Q_{2}\right) K$ Because it's about the increment function, so,

$$
\begin{array}{lll}
K>K^{*}(1) & \text { I f }, & \text { t h e n ; } \\
\pi^{e}\left(Q_{1 e}^{*}, Q_{2 e}^{*}\right)>\pi^{n}\left(Q_{1}^{*}, Q_{2}^{*}\right) \geq \pi^{K}\left(Q_{1 K}^{*}, Q_{2 K}^{*}\right) . & & \\
K=K^{*}(2) & \text { I f }, & \text { t h e n ; } \\
\pi^{e}\left(Q_{1 e}^{*}, Q_{2 e}^{*}\right)=\pi^{n}\left(Q_{1}^{*}, Q_{2}^{*}\right)>\pi^{K}\left(Q_{1 K}^{*}, Q_{2 K}^{*}\right) . &
\end{array}
$$


$K<K^{*} \quad$ I f , $\quad$ t $\mathrm{h}$ e $\mathrm{n}$, $\pi^{n}\left(Q_{1}^{*}, Q_{2}^{*}\right)>\pi^{e}\left(Q_{1 e}^{*}, Q_{2 e}^{*}\right) \geq \pi^{K}\left(Q_{1 K}^{*}, Q_{2 K}^{*}\right)$.

The certificate is over.

Proposition 3 proves that:

Construct the Lagrange function:

$L^{t}\left(\mathbf{Q}_{\mathbf{t}}, \mathbf{T}, \lambda\right)$

$$
\begin{aligned}
= & \sum_{i=1}^{2}\left(\left(p_{i}+r_{i}-c_{i}\left(T_{i}\right)\right) Q_{i}-\left(p_{i}+r_{i}-v_{i}\right) \int_{0}^{Q_{i}} F_{i}(x) \mathrm{d} x-r_{i} \mu_{i}\right) \\
& +\lambda\left(K-\sum_{i=1}^{2} k_{i}\left(T_{i}\right) Q_{i}\right) .
\end{aligned}
$$

$K-T$ The conditions are:

(Condition 3)

$$
\begin{aligned}
\frac{\partial L^{t}\left(\mathbf{Q}_{\mathbf{t}}, \mathbf{T}, \lambda\right)_{Q_{i t}}}{\partial Q_{i t}} & \left(p_{i}+r_{i}-c_{i}\left(T_{i}\right)\right) \\
& -\left(p_{i}+r_{i}-v_{i}\right) F_{i}\left(Q_{i t}\right)-\lambda k_{i}\left(T_{i}\right) \leq 0,
\end{aligned}
$$

$Q_{i} \geq 0, Q_{i} \frac{\partial L^{t}\left(\mathbf{Q}_{\mathbf{t}}, \mathbf{T}, \lambda\right) Q_{i t}}{\partial Q_{i}}=0$.

(Condition 4)

$$
\begin{aligned}
\frac{\partial L^{t}\left(\mathbf{Q}_{\mathbf{t}}, \mathbf{T}, \lambda\right)_{T_{i}}}{\partial T_{i}} & =-\left(\frac{\partial c_{i}\left(T_{i}\right)}{\partial T_{i}}+\lambda \frac{\partial k_{i}\left(T_{i}\right)}{\partial T_{i}}\right) Q_{i t} \\
& =0, T_{i}>0, T_{i} \frac{\partial L^{t}\left(\mathbf{Q}_{\mathbf{t}}, \mathbf{T}, \lambda\right)_{T_{i}}}{\partial T_{i}}=0 .
\end{aligned}
$$

(Condition 5)

$\frac{\partial L^{t}\left(\mathbf{Q}_{\mathbf{t}}, \mathbf{T}, \lambda\right)_{\lambda}}{\partial \lambda}=K-\sum_{i=1}^{2} k_{i}\left(T_{i}\right) Q_{i t} \geq 0, \lambda \geq 0, \lambda \frac{\partial L^{t}\left(\mathbf{Q}_{\mathbf{t}}, \mathbf{T}, \lambda\right)_{\lambda}}{\partial \lambda}=0$.

$\lambda=0 K-T(1)$ Conditional knowledge. The above conditions can be translated into:

$$
\left\{\begin{array}{l}
\left(p_{i}+r_{i}-c_{i}\left(T_{i}\right)\right)-\left(p_{i}+r_{i}-v_{i}\right) F_{i}\left(Q_{i}\right)=0 ; i=1,2 \\
-\frac{\partial c_{i}\left(T_{i}\right)}{\partial T_{i}} Q_{i}=0 ; i=1,2
\end{array} .\right.
$$

Because the problem is concave planning, the above equations are established. $Q_{1 t}^{1 *} Q_{2 t}^{1 *} T_{1 t}^{1 *} T_{2 t}^{1 *}$.

$\lambda \neq 0 K-T(2)$ Conditional knowledge. The above conditions can be translated into:

$$
\left\{\begin{array}{l}
\left(p_{i}+r_{i}-c_{i}\left(T_{i}\right)\right)-\left(p_{i}+r_{i}-v_{i}\right) F_{i}\left(Q_{i}\right)-\lambda k_{i}\left(T_{i}\right)=0 ; i=1,2 \\
-\left(\frac{\partial c_{i}\left(T_{i}\right)}{\partial T_{i}}+\lambda \frac{\partial k_{i}\left(T_{i}\right)}{\partial T_{i}}\right) Q_{i}=0 ; i=1,2 \\
K-\sum_{i=1}^{2} k_{i}\left(T_{i}\right) Q_{i}=0
\end{array}\right.
$$

Because the problem is concave planning, the above equations are established. $Q_{1 t}^{2 *} Q_{2 t}^{2 *} T_{1 t}^{2 *} T_{2 t}^{2 *} \lambda_{t}^{2 *}$.

$\lambda=0 \quad Q_{1 t}^{1 *} Q_{2 t}^{1 *} \quad T_{1 t}^{1 *} \quad T_{2 t}^{1 *} K-T \quad Q_{1 t}^{1 *}<Q_{1}^{*} \quad Q_{2 t}^{1 *}<Q_{2}^{*}$ $Q_{i t}^{1 *} ; i=1,2 T_{1 t}^{1 *} T_{2 t}^{1 *} \lambda=0$ It can be seen from (1) that when the cost structure satisfies the formula 6 , the optimal production of the manufacturing enterprise is 0 , and the optimal green technology input level is 0 . At the same time, it can be seen from (1) that when the manufacturing enterprise increases the unit carbon quota input in the optimal output, the profit is zero, and there is the carbon emission right surplus at this time, and the remaining amount is: $W^{*}=K-\sum_{i=1}^{2} k_{i}\left(T_{i t}^{1 *}\right) Q_{i t}^{1 *}$. However, because in this case, the remaining carbon emission rights generated by manufacturing enterprises can not be sold through the external carbon emission permits trade market, so manufacturing enterprises will not invest in green technology. At this time, the optimal production decision of the manufacturing enterprise degenerates into the green technology input, the optimal production quantity and the optimal green technology input level without carbon emissions limits constraint. $Q_{i t}^{*}=Q_{i}^{*} ; i=1,2 T_{i}^{*}=0 ; i=1,2$

$$
\lambda \neq 0 \quad Q_{1 t}^{2 *} Q_{2 t}^{2 *} T_{1 t}^{2 *} T_{2 t}^{2 *} \lambda_{t}^{2 *} K-T Q_{1 t}^{2 *}<Q_{1}^{*} Q_{2 t}^{2 *}<Q_{2}^{*}
$$

$Q_{i t}^{2 *}, i=1,2 T_{1 t}^{*} \in(0,1) ; T_{2 t}^{*} \in(0,1) \lambda \neq 0$ from $(2)$, we can see that when is a point, and, when the cost structure satisfies formula 7 , the optimal production capacity and the optimal green technology input level of the manufacturing enterprise are respectively,. At the same time, it can be seen from (2) that when the manufacturing enterprise increases the unit carbon quota input in the optimal output, the profit is positive, but at this point, the manufacturing enterprise's production is limited by formula 7 , and the manufacturing enterprise's production decision should be consistent. The remaining carbon emission rights of manufacturing enterprises are zero $K-T K-\sum_{i=1}^{2} k_{i}\left(T_{i t}^{2 *}\right) Q_{i t}^{2 *}=0$.

Therefore, under the constraint of carbon emissions limits, manufacturing enterprises make green technology input decision, there is an optimal production and optimal green technology input level, and the cost structure satisfies formula $7 . Q_{i t}^{*} ; i=1,2 T_{i}^{*} ; i=1,2$.

The certificate is over.

Corollary 5 proves that:

$K \geq \sum_{i=1}^{2} k_{i} Q_{i}^{*}$. (1) When the carbon emissions of the manufacturing enterprise are lower than the carbon emissions limits set by the government, the production decision of the enterprise is not affected by the carbon emissions limits set by the government, and the green technology input level of the enterprise. From this, $T_{i}^{*}=0 ; i=1,2$ $Q_{1 K}^{*}=Q_{1 t}^{*}=Q_{1}^{*} ; Q_{2 K}^{*}=Q_{2 t}^{*}=Q_{2}^{*}$.

$K<\sum_{i=1}^{2} k_{i} Q_{i}^{*}$. (2) When the emissions of manufacturing enterprises are subject to the government carbon emissions limits, enterprises will carry out green technology input, green technology input level, so: $T^{*} \in(0,1)$. 


$$
\begin{gathered}
F^{-1}\left(\frac{p_{1}+r_{1}-c_{1}}{p_{1}+r_{1}-v_{1}}\right)>F^{-1}\left(\frac{p_{1}+r_{1}-c_{1}\left(T_{1}^{*}\right)}{p_{1}+r_{1}-v_{1}}\right) \\
=\frac{K-k_{2}\left(T_{2}\right) Q_{2}}{k_{1}\left(T_{1}\right)}>\frac{K-k_{2} Q_{2}}{k_{1}}, \\
F^{-1}\left(\frac{p_{2}+r_{2}-c_{2}}{p_{2}+r_{2}-v_{2}}\right)>F^{-1}\left(\frac{p_{2}+r_{2}-c_{2}\left(T_{2}\right)}{p_{2}+r_{2}-v_{2}}\right) \\
=\frac{K-k_{1}\left(T_{1}\right) Q_{1}}{k_{2}\left(T_{2}\right)}>\frac{K-k_{1} Q_{1}}{k_{2}} .
\end{gathered}
$$

From this, $Q_{1 K}^{*}<Q_{1 t}^{*}<Q_{1}^{*} ; Q_{2 K}^{*}<Q_{2 t}^{*}<Q_{2}^{*}$.

The certificate is over.

Corollary 6 proves that:

When enterprises only make green technology input decisions under the constraint of carbon emissions limits, manufacturing enterprises will not make green technology input. At that time, enterprises will carry out green technology into water, there are $K \geq \sum_{i=1}^{2} k_{i} Q_{i}^{*}, K<\sum_{i=1}^{2} k_{i} Q_{i}^{*}, \pi^{t}\left(\mathbf{Q}_{\mathbf{t}}^{*}, \mathbf{T}^{*}\right)=\pi^{n}\left(\mathbf{Q}_{\mathbf{t}}^{*}\right)$ $-\left(\left(c_{1}\left(T_{1}\right)-c_{1}\right) \frac{K-k_{2} Q_{2}}{k_{1}}+\left(c_{2}\left(T_{2}\right)-c_{2}\right) \frac{K-k_{1} Q_{1}}{k_{2}}\right)$.

$Q_{i K}^{*} \leq Q_{i}^{*}, Q_{i t}^{*} \leq Q_{i}^{*}$ From Corollary 5 , we can get, therefore,

$$
\begin{aligned}
& \text { w e } \quad\left(\left(c_{1}\left(T_{1}\right)-c_{1}\right) \frac{K-k_{2} Q_{2}}{k_{1}}+\left(c_{2}\left(T_{2}\right)-c_{2}\right) \frac{K-k_{1} Q_{1}}{k_{2}}\right) \leq \pi^{n}\left(\mathbf{Q}^{*}\right) \\
& , \pi^{t}\left(\mathbf{Q}_{\mathbf{t}}^{*}, \mathbf{T}^{*}\right) \leq \pi^{n}\left(\mathbf{Q}^{*}\right), \pi^{K}\left(\mathbf{Q}_{\mathbf{K}}^{*}\right)=\pi^{n}\left(\mathbf{Q}_{\mathbf{K}}^{*}\right) \leq \pi^{*}\left(\mathbf{Q}^{*}\right) . \\
& \pi^{t}\left(\mathbf{Q}_{\mathbf{t}}^{*}, \mathbf{T}^{*}\right)-\pi^{n}\left(\mathbf{Q}_{\mathbf{K}}^{*}\right)=\pi^{n}\left(\mathbf{Q}_{\mathbf{t}}^{*}\right)-\pi^{K}\left(\mathbf{Q}_{\mathbf{K}}^{*}\right)- \\
& \quad\left(\left(c_{1}\left(T_{1}\right)-c_{1}\right) \frac{K-k_{2} Q_{2}}{k_{1}}+\left(c_{2}\left(T_{2}\right)-c_{2}\right) \frac{K-k_{1} Q_{1}}{k_{2}}\right)
\end{aligned}
$$$$
T_{i}=0 \text { Again, if, then, } \pi^{t}\left(\mathbf{Q}_{\mathbf{t}}^{*}, \mathbf{T}^{*}\right)-\pi^{K}\left(\mathbf{Q}_{\mathbf{K}}^{*}\right)=0 \text {. }
$$$$
\pi^{n}\left(\mathbf{Q}_{\mathbf{t}}^{*}\right)-\pi^{n}\left(\mathbf{Q}_{\mathbf{K}}^{*}\right)>\left(\left(c_{1}\left(T_{1}\right)-c_{1}\right) \frac{K-k_{2} Q_{2}}{k_{1}}+\left(c_{2}\left(T_{2}\right)-c_{2}\right) \frac{K-k_{1} Q_{1}}{k_{2}}\right)
$$

$\pi^{t}\left(\mathbf{Q}_{\mathbf{t}}^{*}, \mathbf{T}^{*}\right) \geq \pi^{K}\left(\mathbf{Q}_{\mathbf{K}}^{*}\right)=\pi^{K}\left(\mathbf{Q}_{\mathbf{K}}^{*}, \mathbf{0}\right)(1)$ At that time, when available, green technology input could increase the expected profits of the manufacturing enterprise under the carbon emissions limits, $\pi^{K}\left(\mathbf{Q}_{\mathbf{K}}^{*}\right) \leq \pi^{t}\left(\mathbf{Q}_{\mathbf{t}}^{*}, \mathbf{T}^{*}\right)$.

$$
\pi^{n}\left(\mathbf{Q}_{\mathbf{t}}^{*}\right)-\pi^{n}\left(\mathbf{Q}_{\mathbf{K}}^{*}\right)=\left(\left(c_{1}\left(T_{1}\right)-c_{1}\right) \frac{K-k_{2} Q_{2}}{k_{1}}+\left(c_{2}\left(T_{2}\right)-c_{2}\right) \frac{K-k_{1} Q_{1}}{k_{2}}\right)
$$

$\pi^{t}\left(\mathbf{Q}_{\mathbf{t}}^{*}, \mathbf{T}^{*}\right)=\pi^{K}\left(\mathbf{Q}_{\mathbf{K}}^{*}\right)=\pi^{K}\left(\mathbf{Q}_{\mathbf{K}}^{*}, \mathbf{0}\right)(2)$ At that time, when available, the green technology investment would not increase the expected profits of the manufacturing enterprise under the carbon emissions limits, $\pi^{K}\left(\mathbf{Q}_{\mathbf{K}}^{*}\right)=\pi^{t}\left(\mathbf{Q}_{\mathbf{t}}^{*}, \mathbf{T}^{*}\right)$.

$$
\pi^{n}\left(\mathbf{Q}_{\mathbf{t}}^{*}\right)-\pi^{n}\left(\mathbf{Q}_{\mathbf{K}}^{*}\right)<\left(\left(c_{1}\left(T_{1}\right)-c_{1}\right) \frac{K-k_{2} Q_{2}}{k_{1}}+\left(c_{2}\left(T_{2}\right)-c_{2}\right) \frac{K-k_{1} Q_{1}}{k_{2}}\right)
$$

$\pi^{t}\left(\mathbf{Q}_{\mathbf{t}}^{*}, \mathbf{T}^{*}\right) \leq \pi^{K}\left(\mathbf{Q}_{\mathbf{K}}^{*}\right)=\pi^{K}\left(\mathbf{Q}_{\mathbf{K}}^{*}, \mathbf{0}\right)(3)$ At that time, when available, green technology investment will only reduce the expected profits of production enterprises under the carbon emissions limits, so no green technology investment will be carried out at this time, $\pi^{K}\left(\mathbf{Q}_{\mathbf{K}}^{*}\right)=\pi^{t}\left(\mathbf{Q}_{\mathrm{t}}^{*}, \mathbf{T}^{*}\right)$.

To sum up: $\pi^{K}\left(\mathbf{Q}_{\mathbf{K}}^{*}\right) \leq \pi^{t}\left(\mathbf{Q}_{\mathbf{t}}^{*}, \mathbf{T}^{*}\right) \leq \pi^{n}\left(\mathbf{Q}^{*}\right)$.

The certificate is over.

Proposition 4 proves that:
$W=\sum_{i=1}^{2} k_{i}\left(T_{i c}\right) Q_{i c}-K$ According to formula (6), the expected profit function of a manufacturing enterprise is:

$$
\begin{aligned}
\pi^{c}\left(\mathbf{Q}_{\mathbf{c}}, \mathbf{T}_{\mathbf{c}}\right) & \\
= & \sum_{i=1}^{2}\left(\left(p_{i}+r_{i}-c_{i}\left(T_{i c}\right)\right) Q_{i c}-\left(p_{i}+r_{i}-v_{i}\right) \int_{0}^{Q_{i c}} F_{i}(x) d x-r_{i} \mu_{i}\right) \\
& -w\left(\sum_{i=1}^{2} k_{i}\left(T_{i c}\right) Q_{i c}-K\right) .
\end{aligned}
$$

$\pi^{c}(\mathbf{Q}, \mathbf{T}) Q_{i c} ; i=1,2$ For the first-order partial derivation:

$$
\begin{aligned}
\frac{\partial \pi^{c}\left(\mathbf{Q}_{\mathbf{c}}, \mathbf{T}_{\mathbf{c}}\right)_{Q_{i c}}}{\partial Q_{1 c}}= & \left(p_{1}+r_{1}-c_{1}\left(T_{1 c}\right)\right)-\left(p_{1}+r_{1}-v_{1}\right) F\left(Q_{1 c}\right) \\
& -w k_{1}\left(T_{1 c}\right) .
\end{aligned}
$$

$$
\begin{aligned}
\frac{\partial \pi^{c}\left(\mathbf{Q}_{\mathbf{c}}, \mathbf{T}_{\mathbf{c}}\right)_{Q_{i c}}}{\partial Q_{2 c}}= & \left(p_{2}+r_{2}-c_{2}\left(T_{2 c}\right)\right)-\left(p_{2}+r_{2}-v_{2}\right) F\left(Q_{2 c}\right) \\
& -w k_{2}\left(T_{2 c}\right) .
\end{aligned}
$$

$\pi^{c}\left(\mathbf{Q}_{\mathbf{c}}, \mathbf{T}_{\mathbf{c}}\right) Q_{i c} ; i=1,2$ The second-order partial derivation is obtained:

$$
\frac{\partial^{2} \pi^{c}\left(\mathbf{Q}_{\mathbf{c}}, \mathbf{T}_{\mathbf{c}}\right)_{Q_{i c}}}{\partial Q_{1 c}^{2}}=-\left(p_{1}+r_{1}-v_{1}\right) f\left(Q_{1 c}\right)<0 .
$$

$\frac{\partial^{2} \pi^{c}\left(\mathbf{Q}_{\mathbf{c}}, \mathbf{T}_{\mathbf{c}}\right)_{Q_{i c}}}{\partial Q_{2 c}^{2}}=-\left(p_{2}+r_{2}-v_{2}\right) f\left(Q_{2 c}\right)<0$.

$\frac{\partial^{2} \pi^{c}\left(\mathbf{Q}_{\mathbf{c}}, \mathbf{T}_{\mathbf{c}}\right)_{Q_{i c}}}{\partial Q_{1 c} \partial Q_{2 c}}=\frac{\partial^{2} \pi^{c}\left(\mathbf{Q}_{\mathbf{c}}, \mathbf{T}_{\mathbf{c}}\right)_{Q_{i c}}}{\partial Q_{2 c} \partial Q_{1 c}}=0$.

Further to the Hessian matrix:

$$
\begin{aligned}
& \left|\begin{array}{ll}
\frac{\partial^{2} \pi^{c}\left(\mathbf{Q}_{\mathbf{c}}, \mathbf{T}_{\mathbf{c}}\right)_{Q_{i c}}}{\partial Q_{1 c}^{2}} & \frac{\partial^{2} \pi^{c}\left(\mathbf{Q}_{\mathbf{c}}, \mathbf{T}_{\mathbf{c}}\right)_{Q_{i c}}}{\partial Q_{1} Q_{2}} \\
\frac{\partial^{2} \pi^{c}\left(\mathbf{Q}_{\mathbf{c}}, \mathbf{T}_{\mathbf{c}}\right)_{Q_{i c}}}{\partial Q_{2 c} Q_{1 c}} & \frac{\partial^{2} \pi^{c}\left(\mathbf{Q}_{\mathbf{c}}, \mathbf{T}_{\mathbf{c}}\right)_{Q_{i c}}}{\partial Q_{2 c}^{2}}
\end{array}\right| \\
& \quad=\left(p_{1}+r_{1}-v_{1}\right) f\left(Q_{1 c}\right)\left(p_{2}+r_{2}-v_{2}\right) f\left(Q_{2 c}\right)>0 .
\end{aligned}
$$

$\pi^{c}(\mathbf{Q}, \mathbf{T}) Q_{1 c} Q_{2 c} i$ It can be seen that the optimal production of the product is obtained by the concave function of the sum:

$Q_{i c}^{*}=F^{-1}\left(\frac{p_{i}+r_{i}-c_{i}\left(T_{i c}\right)-w k_{i}\left(T_{i c}\right)}{p_{i}+r_{i}-v_{i}}\right) ; i=1,2$.

Its green technology optimal green technology input level decision model is as follows: 


$$
\begin{aligned}
& \pi^{c}\left(\mathbf{Q}_{\mathbf{c}}, \mathbf{T}_{\mathbf{c}}\right) \\
& =\left(p_{1}+r_{1}-c_{1}\left(T_{1 c}\right)\right) Q_{1 c}^{*}-\left(p_{1}+r_{1}-v_{1}\right) \int_{0}^{Q_{1 c}^{*}} F_{1}(x) \mathrm{d} x-r_{1} \mu_{1} \\
& +\left(p_{2}+r_{2}-c_{2}\left(T_{2 c}\right)\right) Q_{2 c}^{*}-\left(p_{2}+r_{2}-v_{2}\right) \int_{0}^{Q_{2 c}^{*}} F_{2}(x) d x-r_{2} \mu_{2} \\
& -w\left(\sum_{i=1}^{2} k_{i c}\left(T_{i c}\right) Q_{i c}-K\right) \text {. } \\
& \frac{\partial \pi^{c}\left(\mathbf{Q}_{\mathbf{c}}, \mathbf{T}_{\mathbf{c}}\right)_{T_{i c}}}{\partial T_{1 c}}=-\left(c_{1}^{\prime}\left(T_{1 c}\right)+w k_{1}^{\prime}\left(T_{1 c}\right)\right) Q_{1 c}^{*} . \\
& \frac{\partial \pi^{c}\left(\mathbf{Q}_{\mathbf{c}}, \mathbf{T}_{\mathbf{c}}\right)_{T_{i c}}}{\partial T_{2 c}}=-\left(c_{2}^{\prime}\left(T_{2 c}\right)+w k_{2}^{\prime}\left(T_{2 c}\right)\right) Q_{2 c}^{*} . \\
& \frac{\partial^{2} \pi^{c}\left(\mathbf{Q}_{\mathbf{c}}, \mathbf{T}_{\mathbf{c}}\right)_{T_{i c}}}{\partial T_{1 c}^{2}} \\
& =-\left(c^{\prime \prime}\left(T_{1 c}\right)+w k_{1}^{\prime \prime}\left(T_{1 c}\right)\right) Q_{1 c}^{*} \\
& +\left(c_{1}^{\prime}\left(T_{1 c}\right)+w k_{1}^{\prime}\left(T_{1 c}\right)\right) \frac{c_{1}^{\prime}\left(T_{1 c}\right)+w k_{1}^{\prime}\left(T_{1 c}\right)}{p_{1}+r_{1}-v_{1}} f^{-1}\left(Q_{1 c}^{*}\right) \text {. }
\end{aligned}
$$

$$
\begin{aligned}
& \frac{\partial^{2} \pi^{c}\left(\mathbf{Q}_{\mathbf{c}}, \mathbf{T}_{\mathbf{c}}\right)_{T_{i c}}}{\partial T_{2 c}^{2}} \\
& =-\left(c^{\prime \prime}\left(T_{2 c}\right)+w k_{2}^{\prime \prime}\left(T_{2 c}\right)\right) Q_{2 c}^{*} \\
& \quad+\left(c_{2}^{\prime}\left(T_{2 c}\right)+w k_{2}^{\prime}\left(T_{2 c}\right)\right) \frac{c_{2}^{\prime}\left(T_{2 c}\right)+w k_{2}^{\prime}\left(T_{2 c}\right)}{p_{2}+r_{2}-v_{2}} f^{-1}\left(Q_{2 c}^{*}\right) .
\end{aligned}
$$

If there is such that, because, then: $T_{1 c}^{*} \frac{\partial \pi^{c}\left(\mathbf{Q}_{\mathbf{c}}, \mathbf{T}_{\mathbf{c}}\right)_{T_{i c}}}{\partial T_{1 c}}=0 T_{2 c}^{*}$ $\frac{\partial \pi^{c}\left(\mathbf{Q}_{\mathbf{c}}, \mathbf{T}_{\mathbf{c}}\right)_{T_{i c}}}{\partial T_{2 c}}=0 \quad c_{1}^{\prime \prime}\left(T_{1 c}\right) \geq 0 \quad k_{1}^{\prime \prime}\left(T_{2 c}\right) \geq 0 \quad c_{2}^{\prime \prime}\left(T_{2 c}\right) \geq 0$ $k_{2}^{\prime \prime}\left(T_{2 c}^{2 c}\right) \geq 0$.

$$
\frac{\partial^{2} \pi^{c}\left(\mathbf{Q}_{\mathbf{c}}, \mathbf{T}_{\mathbf{c}}\right)_{T_{i c}}}{\partial T_{1 c}^{2}}=-\left(c_{1}^{\prime}\left(T_{1 c}\right)+w k_{1}^{\prime}\left(T_{1 c}\right)\right) Q_{1 c}^{*}<0 ;
$$

$\frac{\partial^{2} \pi^{c}\left(\mathbf{Q}_{\mathbf{c}}, \mathbf{T}_{\mathbf{c}}\right)_{T_{i c}}}{\partial T_{2 c}^{2}}=-\left(c_{2}^{\prime}\left(T_{2 c}\right)+w k_{2}^{\prime}\left(T_{2 c}\right)\right) Q_{2 c}^{*}<0$.

$$
\frac{\partial \pi^{c}\left(\mathbf{Q}_{\mathbf{c}}, \mathbf{T}_{\mathbf{c}}\right)_{T_{i c}}}{\partial T_{1 c}}=0 ; \frac{\partial \pi^{c}\left(\mathbf{Q}_{\mathbf{c}}, \mathbf{T}_{\mathbf{c}}\right)_{T_{i c}}}{\partial T_{2 c}}=0 ; T_{1 c}^{*} T_{2 c}^{*} \text {. Therefore, the }
$$

establishment, that is, the optimal green technology input level for manufacturing enterprises, $T_{1 c}^{*} \in(0,1) T_{2 c}^{*} \in(0,1)$.

At this point, the manufacturing enterprise's optimal production volume:

$$
\begin{gathered}
Q_{1 c}^{*}=F^{-1}\left(\frac{p_{1}+r_{1}-c_{1}\left(T_{1 c}^{*}\right)-w k_{1}\left(T_{1 c}^{*}\right)}{p_{1}+r_{1}-v_{1}}\right) \\
Q_{2 c}^{*}=F^{-1}\left(\frac{p_{2}+r_{2}-c_{1}\left(T_{2 c}^{*}\right)-w k_{1}\left(T_{2 c}^{*}\right)}{p_{2}+r_{2}-v_{2}}\right) . \\
\frac{\partial \pi^{c}\left(\mathbf{Q}_{\mathbf{c}}, \mathbf{T}_{\mathbf{c}}\right)_{Q_{i c}}}{\partial Q_{1 c}}=0 \text { Order, you can draw: }
\end{gathered}
$$

$\frac{\partial \pi^{c}\left(\mathbf{Q}_{\mathbf{c}}, \mathbf{T}_{\mathbf{c}}\right)_{Q_{i c}}}{\partial Q_{1 c}}=\left(p_{1}+r_{1}-c_{1}\right)-\left(p_{1}+r_{1}-v_{1}\right) F\left(Q_{1 c}\right)=w k_{1}\left(T_{1 c}\right)$ available; $\theta_{1}\left(Q_{1 G}^{*}\right)=w$.

$$
\begin{aligned}
& \frac{\partial \pi^{c}\left(\mathbf{Q}_{\mathbf{c}}, \mathbf{T}_{\mathbf{c}}\right)_{Q_{i c}}}{\partial Q_{2 c}}=0 \text { Order, you can draw: } \\
& \frac{\pi^{c}\left(\mathbf{Q}_{\mathbf{c}}, \mathbf{T}_{\mathbf{c}}\right)_{Q_{i c}}}{\partial Q_{2} c}=\left(p_{2}+r_{2}-c_{2}\right)-\left(p_{2}+r_{2}-v_{2}\right) F\left(Q_{2 c}\right)=w k_{2}\left(T_{2 c}\right)
\end{aligned}
$$

available; $\theta_{2}\left(Q_{2 c}^{*}\right)=w$.

$$
\begin{aligned}
& \text { and. } \theta_{1}\left(Q_{1 c}^{*}\right)=\theta_{2}\left(Q_{2 c}^{*}\right)=w . \\
& \frac{\partial \pi^{c}\left(\mathbf{Q}_{\mathbf{c}}, \mathbf{T}_{\mathbf{c}}\right)_{T_{i}}}{\partial T_{1 c}}=-\left(c_{1}^{\prime}\left(T_{1 c}\right)+w k_{1}^{\prime}\left(T_{1 c}\right)\right) Q_{1 c}^{*}=0 \text { Order; can }
\end{aligned}
$$

be drawn, $w=-\frac{c_{1}^{\prime}\left(T_{1}\right)}{k_{1}^{\prime}\left(T_{1}\right)}$.

$$
\frac{\partial \pi^{c}\left(\mathbf{Q}_{\mathbf{c}}, \mathbf{T}_{\mathbf{c}}\right)_{T_{i c}}}{\partial T_{2 c}}=-\left(c_{2}^{\prime}\left(T_{2 c}\right)+w k_{2}^{\prime}\left(T_{2 c}\right)\right) Q_{2 c}^{*}=0 ; \text { It can be }
$$

concluded that, $w=-\frac{c_{2}^{\prime}\left(T_{2}\right)}{k_{2}^{\prime}\left(T_{2}\right)}$.

That is. $\theta_{1}\left(T_{1 c}^{*}\right)=\theta_{2}\left(T_{2 c}^{*}\right)=w$.

At this time, the optimal carbon emission permits trade volume is $W_{c}^{*}=\sum_{i=1}^{2} k_{i}\left(T_{i}\right) Q_{i}-K$.

The certificate is over.

Corollary 7 proves that:

$\theta_{1}\left(Q_{1}\right) Q_{1} \theta_{2}\left(Q_{2}\right) Q_{2}$ Is about the decreasing function, is about the decreasing function. From the above analysis, therefore, $\theta\left(Q_{i}^{*}\right)=0, \theta\left(Q_{i c}^{*}\right)=w, Q_{i}^{*}>Q_{i c}^{*}$.

$\theta\left(Q_{1 K}^{*}\right)=\theta\left(Q_{2 K}^{*}\right)>w(1)$ If so, it can be

o b t a in ed $\theta\left(Q_{1 c}^{*}\right)=\theta\left(Q_{2 c}^{*}\right)<\theta\left(Q_{1 K}^{*}\right)=\theta\left(Q_{2 K}^{*}\right)$ $Q_{1 K}^{*}<Q_{1 c}^{*}<Q_{1}^{*} ; Q_{2 K}^{*}<Q_{2 c}^{*}<Q_{2}^{*}$.

$\theta\left(Q_{1 K}^{*}\right)=\theta\left(Q_{2 K}^{*}\right)=w(2)$ If so, it can be o b t a in ed $\theta\left(Q_{1 c}^{*}\right)=\theta\left(Q_{2 c}^{*}\right)=\theta\left(Q_{1 K}^{*}\right)=\theta\left(Q_{2 K}^{*}\right)$ $Q_{1 c}^{*}=Q_{1 K}^{*}<Q_{1}^{*} ; Q_{2 c}^{*}=Q_{2 K}^{*}<Q_{2}^{*}$.

$\theta\left(Q_{1 K}^{*}\right)=\theta\left(Q_{2 K}^{*}\right)<w(3) \quad$ If $\quad$ s o, $\quad$ s o $\theta\left(Q_{1 c}^{*}\right)=\theta\left(Q_{2 c}^{*}\right)>\theta\left(Q_{1 K}^{*}\right)=\theta\left(Q_{2 K}^{*}\right)$

$Q_{1 c}^{*}<Q_{1 K}^{*}<Q_{1}^{*} ; Q_{2 c}^{*}<Q_{2 K}^{*}<Q_{2}^{*}$.

The certificate is over.

Corollary 8 proves that:

From the foregoing an a ly $\operatorname{sis}: \pi^{c}\left(\mathbf{Q}_{\mathbf{c}}^{*}, \mathbf{T}_{\mathbf{c}}^{*}\right)=\pi^{n}\left(\mathbf{Q}_{\mathbf{c}}^{*}\right)-\sum_{i=1}^{2} w\left(k_{i}\left(T_{i}\right) Q_{i c}^{*}-K\right)$.

$\pi^{c}\left(\mathbf{Q}_{\mathbf{c}}^{*}, \mathbf{T}_{\mathbf{c}}^{*}\right)$ The maximum value of consideration, yes. $\pi^{c}\left(\mathbf{Q}_{\mathbf{c}}^{*}, \mathbf{T}_{\mathbf{c}}^{*}\right) \geq \pi^{n}\left(\mathbf{Q}_{\mathbf{i}}^{*}\right)-\sum_{i=1}^{2} w\left(k_{i} Q_{i}^{*}-K\right)$.

$K \geq \sum_{i=1}^{2} k_{i} Q_{i}^{*}$ If, in this case, therefore, therefore, if, in this case, from the foregoing analysis, we can obtain, therefore,. Combined. $\pi^{n}\left(\mathbf{Q}^{*}\right)=\pi^{K}\left(\mathbf{Q}_{\mathbf{K}}^{*}\right)$ $\pi^{c}\left(\mathbf{Q}_{\mathbf{c}}^{*}, \mathbf{T}_{\mathbf{c}}^{*}\right)-\pi^{K}\left(\mathbf{Q}_{\mathbf{K}}^{*}\right)>-\sum_{i=1}^{2} w\left(k_{i} Q_{i}^{*}-K\right)>0$ $\pi^{c}\left(\mathbf{Q}_{\mathbf{c}}^{*}, \mathbf{T}_{\mathbf{c}}^{*}\right)>\pi^{K}\left(\mathbf{Q}_{\mathbf{K}}^{*}\right)$ $K=\sum_{i=1}^{2} k_{i} Q_{i K}^{*}$ $\pi^{c}\left(\mathbf{Q}_{\mathbf{c}}^{*}, \mathbf{T}_{\mathbf{c}}^{*}\right)-\pi^{K}\left(\mathbf{Q}_{\mathbf{K}}^{*}\right) \geq-\sum_{i=1}^{2} w\left(k_{i} Q_{i K}^{*}-K\right)=0$ $\pi^{c}\left(\mathbf{Q}_{\mathbf{c}}^{*}, \mathbf{T}_{\mathbf{c}}^{*}\right)=\pi^{K}\left(\mathbf{Q}_{\mathbf{K}}^{*}\right) \pi^{c}\left(\mathbf{Q}_{\mathbf{c}}^{*}, \mathbf{T}_{\mathbf{c}}^{*}\right) \geq \pi^{K}\left(\mathbf{Q}_{\mathbf{K}}^{*}\right)$.

$K \leq \sum_{i=1}^{2} k_{i}\left(T_{i}\right) Q_{i c}^{*}$ If, because, so; if, then there is, that is . $\pi^{c}\left(\mathbf{Q}_{\mathbf{c}}^{*}, \mathbf{T}_{\mathbf{c}}^{*}\right)=\pi^{n}\left(\mathbf{Q}_{\mathbf{c}}^{*}\right)-\sum_{i=1}^{2} w\left(k_{i}\left(T_{i}\right) Q_{i c}^{*}-K\right)<\pi^{n}\left(\mathbf{Q}_{\mathbf{c}}^{*}\right)<\pi^{n}\left(\mathbf{Q}^{*}\right)$ $\pi^{c}\left(\mathbf{Q}_{\mathbf{c}}^{*}, \mathbf{T}_{\mathbf{c}}^{*}\right)<\pi^{n}\left(\mathbf{Q}^{*}\right) \quad K>\sum_{i=1}^{2} k_{i}\left(T_{i}\right) Q_{i c}^{*}$ $\pi^{c}\left(\mathbf{Q}_{\mathbf{c}}^{*}, \mathbf{T}_{\mathbf{c}}^{*}\right)>\pi^{n}\left(\mathbf{Q}_{\mathbf{c}}^{*}\right)-\sum_{i=1}^{2} w\left(k_{i}\left(T_{i}\right) Q_{i c}^{*}-K\right)>\pi^{n}\left(\mathbf{Q}^{*}\right)$ $\pi^{c}\left(\mathbf{Q}_{\mathbf{c}}^{*}, \mathbf{T}_{\mathbf{c}}^{*}\right)>\pi^{n}\left(\mathbf{Q}^{*}\right)$.

Therefore, according to the intermediate value theorem, we can see that there is a, so 
that. The reverse solution. $K^{*} \pi^{c}\left(\mathbf{Q}_{\mathbf{c}}^{*}, \mathbf{T}_{\mathbf{c}}^{*}\right)=\pi^{n}\left(\mathbf{Q}^{*}\right)$ $K^{*}=\sum_{i=1}^{2} k_{i}\left(T_{i}\right) Q_{i c}^{*}+\frac{1}{w}\left(\pi^{n}\left(\mathbf{Q}^{*}\right)-\pi^{c}\left(\mathbf{Q}_{\mathbf{c}}^{*}, \mathbf{T}_{\mathbf{c}}^{*}\right)\right)$.

$\pi^{c}(\mathbf{Q}) K$ Because it's about the increment function, so: $K>K^{*} ;$ (1) If, then, $\pi^{c}\left(\mathbf{Q}_{\mathbf{c}}^{*}, \mathbf{T}_{\mathbf{c}}^{*}\right)>\pi^{n}\left(\mathbf{Q}^{*}\right)>\pi^{K}\left(\mathbf{Q}_{\mathbf{K}}^{*}\right)$. $K=K^{*} ;$ (2) If, then,; $\pi^{c}\left(\mathbf{Q}_{\mathbf{c}}^{*}, \mathbf{T}_{\mathbf{c}}^{*}\right)=\pi^{n}\left(\mathbf{Q}^{*}\right)>\pi^{K}\left(\mathbf{Q}_{\mathbf{K}}^{*}\right)$. $K<K^{*}$; (3) If, then, $\pi^{n}\left(\mathbf{Q}^{*}\right)>\pi^{c}\left(\mathbf{Q}_{\mathbf{c}}^{*}, \mathbf{T}_{\mathbf{c}}^{*}\right) \geq \pi^{K}\left(\mathbf{Q}_{\mathbf{K}}^{*}\right)$. The certificate is over.

Open Access This article is licensed under a Creative Commons Attribution 4.0 International License, which permits use, sharing, adaptation, distribution and reproduction in any medium or format, as long as you give appropriate credit to the original author(s) and the source, provide a link to the Creative Commons licence, and indicate if changes were made. The images or other third party material in this article are included in the article's Creative Commons licence, unless indicated otherwise in a credit line to the material. If material is not included in the article's Creative Commons licence and your intended use is not permitted by statutory regulation or exceeds the permitted use, you will need to obtain permission directly from the copyright holder. To view a copy of this licence, visit http://creativecommons.org/licenses/by/4.0/.

\section{References}

1. Abolins J, Gravitis J (2007) Biomass conversion to transportation fuels, combustibles, and nano-materials by steam explosion. Latv J Phys Tech Sci 4:29-39

2. Benjaafar S, Elhafsi M (2011) A production-inventory system with both patient and impatient demand classes. IEEE Trans Autom Sci Eng 9(1):148-159

3. Benjaafar S, Li Y, Daskin M (2012) Carbon footprint and the management of supply chains: insights from simple models. IEEE Trans Autom Sci Eng 10(1):99-116

4. Braun E, Wield D (1994) Regulation as a means for the social control of technology. Technol Anal Strateg Manag 6(3):259-272

5. Chaabane A, Ramudhin A, Paquet M (2012) Design of sustainable supply chains under the emission trading scheme. Int J Prod Econ 135(1):37-49

6. Chen X, Luo Z, Wang X (2017) Impact of efficiency, investment, and competition on low carbon manufacturing. J Clean Prod 143:388-400

7. Chen X, Wang X (2016) Effects of carbon emission reduction policies on transportation mode selections with stochastic demand. Transport Res Part E Logist Transport Rev 90:196-205

8. Chen X, Wang X, Kumar V, Kumar N (2016) Low carbon warehouse management under cap-and-trade policy. J Clean Prod 139:894-904
9. Chen X, Wang X, Zhou M (2019) Firms' green R\&D cooperation behaviour in a supply chain: Technological spillover, power and coordination. Int J Prod Econ 218:118-134

10. Dobos I (2005) The effects of emission trading on production and inventories in the Arrow-Karlin model. Int J Prod Econ 93:301-308

11. Du S, Dong J, Liang L, Zhang J (2009) Optimal production policy with emission permits and trading. Chin J Manag Sci 17(3):81-86

12. He D, Ma H (2011) Strategy of enterprise production and store under constraints of carbon emission. Resour Ind 13(2):63

13. He H, Ma C (2018) The production strategy for two products considering stochastic demand under cap-and-trade regulation. Int J Internet Manuf Serv 5(1):38-50

14. Hua G, Qiao H, Jian L (2011) Optimal order lot sizing and pricing with carbon trade. SSRN 1796507, 3

15. Hua $H$ (2020) Considering price competition in enterprise decisions under a low carbon economy background. Environ Eng Manag J (EEMJ) 19(9)

16. IPCC (2007) Climate change 2007: the physical science basis. https://previa.uclm.es/area/amf/antoine/energias/Ipcc_anotado.pdf

17. Jian M, He H, Ma C, Wu Y, Yang H (2019) Reducing greenhouse gas emissions: a duopoly market pricing competition and cooperation under the carbon emissions cap. Environ Sci Pollut Res 1-8

18. Jiang S (2014) Research on the relationship between industrial carbon emissions and industrial output value. Master Degree, Beijing Forestry University, Beijing

19. Laffont JJ, Tirole J (1996) Pollution permits and compliance strategies. J Public Econ 62(1-2):85-125

20. Li S, Huang C, Gu M, Zhang D (2007) Option game model of firms' investment decisions in new technologies for pollution control based on emission permit trading. Syst Eng Theory Methodol Appl 16(6):701-705

21. Liao Z, Xu C, Cheng H, Dong J (2018) What drives environmental innovation? A content analysis of listed companies in China. J Clean Prod 198:1567-1573

22. Ma C, He H, Luo Z, Wu Y (2017) An inter-temporal production strategy under a carbon trading policy. Environ Eng Manag J (EEMJ) 16(10):2401-2412

23. Ma C, Hou B, Yuan T (2020) Low-carbon manufacturing decisions considering carbon emission trading and green technology input. Environ Eng Manag J (EEMJ) 19(9)

24. Ma C, Li T, Li C, He H (2014) Pricing strategy and governments intervention for green supply chain with strategic customer behavior. J Syst Sci Inf 2(3):206-216

25. Ma C, Liu X, Zhang H, Wu Y (2016) A green production strategies for carbon-sensitive products with a carbon cap policy. Adv Prod Eng Manag 11(3):216-226

26. Yu S (2007) Research on the conception and classification of green technology. J Wuhan Inst Technol 29(5):40-42

27. Zhao D, Lv J (2012) Carbon-efficient strategy for integrated supply chain considering carbon emission rights and trading. Ind Eng Manag 5:65-71 